\title{
Is Multimedia Multisensorial? - A Review of Mulsemedia Systems
}

\author{
ALEXANDRA COVACI, Brunel University London \\ LONGHAO ZOU, Shenzhen University \\ IRINA TAL and GABRIEL-MIRO MUNTEAN, Dublin City University \\ GHEORGHITA GHINEA, Brunel University London
}

\begin{abstract}
Mulsemedia-multiple sensorial media-makes possible the inclusion of layered sensory stimulation and interaction through multiple sensory channels. The recent upsurge in technology and wearables provides mulsemedia researchers a vehicle for potentially boundless choice. However, in order to build systems that integrate various senses, there are still some issues that need to be addressed. This review deals with mulsemedia topics that remain insufficiently explored by previous work, with a focus on the multi-multi (multiple media-multiple senses) perspective, where multiple types of media engage multiple senses. Moreover, it addresses the evolution of previously identified challenges in this area and formulates new exploration directions.
\end{abstract}

CCS Concepts: • General and reference $\rightarrow$ Surveys and overviews; $\bullet$ Human-centered computing $\rightarrow$ Interaction paradigms; Interaction devices; Interaction techniques;

Additional Key Words and Phrases: Mulsemedia, multimedia, multisensory, cross-modal, quality of experience

ACM Reference format:

Alexandra Covaci, Longhao Zou, Irina Tal, Gabriel-Miro Muntean, and Gheorghita Ghinea. 2018. Is Multimedia Multisensorial? - A Review of Mulsemedia Systems. ACM Comput. Surv. 51, 5, Article 91 (September 2018), 35 pages.

https://doi.org/10.1145/3233774

\section{INTRODUCTION}

You are perched atop a motorcycle, speeding through Brooklyn with the wind whipping through your hair. The rattle of the engine rumbles your backside, the handlebars shake to the beat of the road, the sound of the engine and of the surroundings are delivered in full stereo, and an indefinable city whiff hits your nose. Then your tokens run out. You have just experienced the

This article was funded by the European Union's Horizon 2020 Research and Innovation program under Grant Agreement no. 688503 .

Authors' addresses: A. Covaci was with Department of Computer Science, Brunel University London, UK; she is currently with School of Engineering and Digital Arts, University of Kent, Canterbury, UK; email: a.covaci@kent.ac.uk; G. Ghinea, Department of Computer Science, Brunel University London, UK; email: george.ghinea@brunel.ac.uk; I. Tal and G.-M. Muntean, Performance Engineering Laboratory, School of Electronic Engineering, Dublin City University, Dublin, Ireland; email: gabriel.muntean@dcu.ie, irina.tal2@mail.dcu.ie; L. Zou (corresponding author), College of Computer Science \& Software Engineering, Shenzhen University, China; email: longhao.zou@szu.edu.cn.

Permission to make digital or hard copies of all or part of this work for personal or classroom use is granted without fee provided that copies are not made or distributed for profit or commercial advantage and that copies bear this notice and the full citation on the first page. Copyrights for components of this work owned by others than the author(s) must be honored. Abstracting with credit is permitted. To copy otherwise, or republish, to post on servers or to redistribute to lists, requires prior specific permission and/or a fee. Request permissions from permissions@acm.org.

(C) 2018 Copyright held by the owner/author(s). Publication rights licensed to ACM

0360-0300/2018/09-ART91 \$15.00

https://doi.org/10.1145/3233774 
Sensorama Simulator, a machine invented in 1962 by Heilig [100]. In the spirit of Aldous Huxley's Brave New World, where sensory elements were used to heighten the "feely effects" of a movie, Heilig created an immersive environment by playing a 3D film along with stereo sound, scents, and wind. Sensorama stands out as one of the early examples of using technology to create alternate realities. There is an obvious correlation between Sensorama and today's multimedia and virtual reality (VR) projects.

In order for systems like Sensorama to successfully simulate reality, they need to integrate several sensory channels into a unique multisensory experience by following the brain's perceptual mechanisms [111]. VR is becoming a promising framework to immerse people into realistic environments and triggers the development and evaluation of various prototypes, displays, interfaces, and interactions with virtual objects [41, 74, 134]. However, many multimedia systems lack the inclusion of layered sensory stimulation and of interaction through multiple sensorial channels. Alas, over the past years, physically cumbersome technologies have generally restrained the delivery of truly immersive experiences.

In multimedia applications, research and technology developments are generally focused on improving image and/or sound in audiovisual (AV) systems. This limitation of stimuli [61] maintains a level of disconnect between the user and the represented scene. The potential impact on enriching the interaction through combinations of AV with one or several different types of feedback (e.g., haptic, olfactory, gustatory) remains underused in digital media. Moreover, recent advancements in ultra-high-definition video technologies are not sufficient for higher immersion because the simulated senses remain visual and audio-and this, notwithstanding the fact that complementary pieces of multisensory information could push the sensations of immersion way beyond anything experienced so far [35]. Indeed, the importance of sensorial feedback in user immersion has increasingly been studied over the last years, with contributions focused on olfactory [85] and haptic aspects [163].

Mulsemedia was coined as a type of multimedia involving more than three senses in [61]. Back then, just as Sensorama envisaged in the 1960s, the leap toward this transportive world was still difficult because of the effort behind incorporating other senses and the lack of multisensoriality on the devices market. Nowadays, the exponential upsurge in technology and wearables is providing mulsemedia researchers a vehicle for potentially boundless choices. The underpinning technology is becoming incredibly widespread, leading us to head toward a future economic "golden age" of technological convergence in 2020s. The Roto VR chair ${ }^{1}$ offers a Sensorama-like experience where the user can feel wind, heat, scent, and force feedback. Wearables are permanently evolving from their single function of counting the number of daily steps to measuring brain activity and correlating it with specific sounds (Muse headband ${ }^{2}$ ). Kickstarter projects that promise to engage all the senses in various ways have emerged and are trying to find pilot clients and development partners.

The dynamics of these changes motivate the current review that puts multisensory media challenges in an actualized context and illustrates technologies and research problems involved in building systems that integrate various senses. Existent surveys [61, 194] offer a useful introduction to the field of mulsemedia with a focus on applications that have a multisensory dimension. Other works were focused on specific subsets of senses: olfaction $[58,130]$ or haptics [35]. These surveys presented detailed aspects of the production-distribution-rendering workflow, with a scope narrowed down on the addition of one sense. However, this article has a wider remit (illustrated in Figure 1) than the aforementioned surveys and brings a new perspective on mulsemedia, situating

\footnotetext{
${ }^{1}$ Roto VR: http://www.rotovr.com.

${ }^{2}$ Muse Headband: http://www.choosemuse.com/.
} 


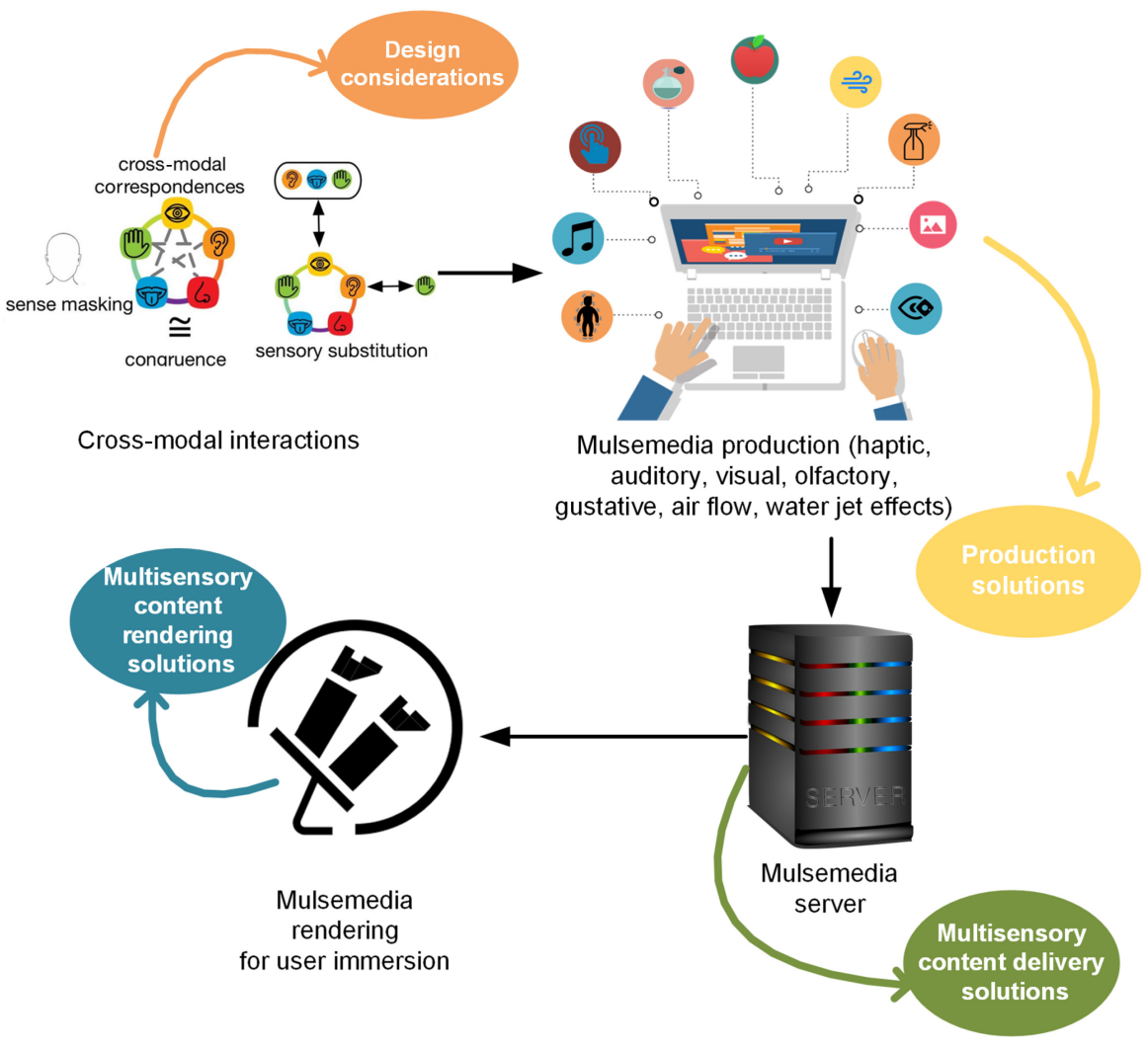

Fig. 1. The main directions of the survey.

the technical problem of communicating via multiple senses within the underlying affordances of human sensory and cognitive systems.

In the present review, we extend the work carried out in previous multisensory surveys and address aspects that should be taken into consideration when starting to develop mulsemedia systems. Moreover, we show how our perception is influenced by senses, and how we can substitute a sense with a combination of other senses or what happens when a sensory stimulus is stronger than the others. We believe that cross-modal correspondences should be considered alongside semantic, temporal, and spatial congruency in the design of products from food experiences to mulsemedia systems because they solve the cross-modal binding problem, generate our unique perceptual experience, and could aid in the rehabilitation of people with sensory impairments through the use of sensory substitution devices. Importantly, while models of multisensory perception and processing have been proposed in the literature $[9,17]$, there is relatively little work focusing on how one maps such models into the digital realm of mulsemedia, and this is the main remit of the work reported in this article. This survey follows four main directions, as depicted in Figure 1, such as (1) offering a set of information about different types of congruences that people who design mulsemedia systems could reflect on. In the remainder of the article, we focus on design issues related to the (2) production - (3) distribution - (4) rendering chain as we synthesize available software and hardware solutions for building mulsemedia systems. Thus, we supplement the aforementioned surveys by focusing on specific challenges and solutions characteristic of all phases of the mulsemedia workflow and we identify some potential areas for future research in the area. 
This article is thus a comprehensive, up-to-date survey of research on mulsemedia systems that aims to provide the research community with detailed insight on this relatively new research field. Additionally, our aim is to provide fundamental guidelines and knowledge for allowing readers to start designing or performing experiments with such systems. This work comprises the following main contributions:

- A thorough analysis of the current state of the art in mulsemedia systems with emphasis on their challenges

- An overview of different opportunities that provide designers and developers a starting point in creating meaningful mulsemedia systems where they make use of a wide spectrum of sensory experiences

- A discussion of the challenges of enriching digital content with multisensory features in different phases of the production-distribution-rendering workflow

- Identification and discussion of future challenges/research directions

\section{MULTISENSORY PERCEPTION AND INTERACTION}

We rarely experience senses in isolation. Real-world events produce different sensory signals that comprise our perceptual experience as a coherent percept through the integration of information from various independent channels. Multisensory interactions occur at the intersection of two or more sensory modalities and are essential in constructing a meaningful representation of the environment. Humans are equipped with multiple senses in order to sense the available information; thus, it is likely that our brain has evolved to learn, adapt, and operate optimally in multisensory settings. The process of multisensory integration describes the synergy among the senses and the fusion of their information content. Multisensory integration is more likely to occur under time and space coincidence constraints and it is enhanced by semantic and synesthetic congruency on multisensory information processing [186]. The key idea is that we can use the findings and research methods from the field of cognitive science to benefit the process of design and evaluation of cross-modal mappings for multimodal user interaction and information display. Exploring the multisensory phenomena in human-computer interaction (HCI) might lead to the development of more intelligent and adaptive user interfaces. In this section, (1) we look at multisensory processing with a focus on the benefits of multisensory stimulation, and (2) we explore the relevance of cross-modal correspondences in the design process with a focus on how multisensory technologies could transform the way we interact and experience.

\subsection{Selection of Human Senses}

When it comes to the number of senses that could be mixed in building a multisensory system, the answer could be anything between five (the Aristotelian senses) and 21 [46]. Exteroceptive senses, corresponding to a sense organ, are that of sight, hearing, taste, smell, and touch (tactile/haptic). Sensation is carried out by these sense organs that convert energy from the environment to an electrical pulse. This electrical signal is transmitted to the brain, where it is processed and interpreted, creating a perception. However, humans also have interoceptive capabilities that make them aware of the internal state of the body. These can be broken down into the following categories [64]:

- Equilibrioception contributes in helping us maintain our balance. Although vision plays a main role in this sense, the vestibular system of the internal ear provides the leading contribution to the sense of balance and spatial orientation.

- Nociception is the sense of pain. Seen initially as an experience related to touch, recent research showed that this phenomenon corresponds to a specific area of the brain [45]. 
- Proprioception is the awareness of the position of our body. This kinesthetic sense is responsible for conveying information of where our body parts are, even if we cannot see them.

- Thermoception is the sense of heat and cold that relies on the temperature sensors in our skin.

- Temporal perception is related to the perception of time. Although this can be subjective, research shows that our basal ganglia and other parts of the brain are responsible for it [53].

- Interoception conveys information about our visceral sensory receptors found in our internal organs.

Consistency between proprioceptive information and sensory feedback is essential when building effective environments, increasing the sense of immersion. VR systems like the "Amphibian" SCUBA simulator, developed by the MIT Media Lab, engage sensory modalities additional to AV like thermoception, equilibrioception, and proprioception [88]. Users wear an Oculus Rift headmounted display and headphones that allow them to see and hear the underwater environment. Buoyancy, drag, and temperature are simulated through various sensors. Participants have Peltier modules attached to their wrists to simulate temperature changes as they dive deeper into the water and use an inflatable airbag placed under their torso that allows them to control ascent or descent through breathing while the movements of their virtual representation are synchronized. However, despite the efforts of the community, interoceptive senses have made little progress.

Through the synthesis and fusion of different sensory signals, multisensory integration creates a coherent and unified perceptual evaluation of our surroundings [190]. To successfully combine signals from different sensory channels, the brain needs to solve a correspondence problem, integrate the related information, and dynamically adapt to spatial or temporal conflicts across senses [189]. Each sense has its own sphere and it is important in a different context. Choosing the appropriate sensing channels should be determined by environmental constraints and by the tasks or information the user has to handle or his or her abilities.

\subsection{Multisensory Processing}

HCI studies, most specifically in cognitive load theory, Gestalt theory, or Baddeley's model of working memory, illustrate many advantages of designing multisensory interfaces $[8,149,150]$. Findings in cognitive science related to multimodal interaction show that providing an individual with multiple sensory cues expands processing capabilities and leads to faster acquisition and retention of information [179]. Research demonstrated that the presentation of nonvisual cues (e.g., tactile, auditory, audiotactile) has a beneficial impact on the performance in visual tasks [205]. Moreover, it was shown that in certain circumstances, nonvisual warning signals provided benefits that visual cues cannot offer [205].

Little research has investigated how multisensory information is represented in working memory. In [200], the authors used cross-modal stimuli in their study and found an improvement of free recall of cross-modal audiovisual stimuli compared to modality-specific, audio, or visual stimuli. These findings suggest that the combination of information from different modalities (not the redundancy) leads to an improved memory performance. The advantage of cross-modal object recall can be explained through the dual-coding theory.

Having as a starting point the generative and the dual-coding theory, Mayer proposed a model of multimedia learning, where visual animations that were accompanied with audio information led to a split-attention effect in which students learned better [115]. This model consists of three analogous processes that take place in the dual planes: selection-here the user selects relevant information from the sense receptors into visual and verbal short-term memory; organization- 
involves a dual process of knowledge transformation within the respective short-term memories; and integration-where one builds one-to-one references between the verbal and textual facets of the information. This process takes place in working memory, which is part of the short-term memory. However, it must be borne in mind that, due to the limited capacity of short-term memory, integration of the visual and verbal models is constrained by the memory load. At this stage, information has the potential to be absorbed into long-term storage, but it usually requires effort on the part of the learner.

Hypermedia learning depends strongly on individuals' spatial ability, i.e., their ability to mentally map out the information presented to them, complete with the locations and routes of the hypertext structure. Very often, individuals with high spatial ability create interior maps, which are superior to the ones provided externally. This prevents disorientation and reduces the cognitive overload that might potentially be experienced [154]. Learners attend differently to various stimuli and invest intellectual effort accordingly. Thus, learners invest more mental effort in media that they perceive to be difficult than in those perceived as being easy. This would suggest the use of contrived methods such as highlighting in order to grab and direct the attention of the viewer [154]. Video and audio can be successfully used in a multimedia environment to improve the quality of learning as long as they do not compete for the same processing resources. Indeed, concomitant video events can help users filter out unnecessary sound effects and focus on relevant audio information [70]. These findings were applied to educational interface design based on user-centered principles and were shown to minimize the cognitive load and to lead to better performance [149].

Providing an individual with multiple sensory cues should facilitate a representation; thus, numerous educational programs have advocated the benefits of mutually supportive multisensory information. Indeed, psychologists and neurologists have advanced the field of multisensory perception over recent decades. Research has shown that the facilitative effect in information processing is significantly greater for multisensory stimulus combinations than within-modal combinations [62]. Multisensory processes facilitate memory [126], as well as perceptual and implicit learning and training outcomes [6]. In [68], the authors have shown that multisensory audio/tactile cueing improves the performance (speed and accuracy) of visual search and reduces the amount of mental workload. Multisensory intervention has been successfully used also as a therapy for correcting and improving literacy skills [155] or for increasing sustained and selective attention of people with autism [49]. Moreover, in this case, the multisensory experience was even more effective by increasing students' engagement with people and objects. Technology advances now provide the opportunity to combine and connect neuroscience knowledge with game design thinking, creating toolkits for learning, training, and therapy.

\subsection{Cognitive Foundations}

Multisensory integration combines information from different sensory channels with positive effects on accuracy, precision, and reaction times. Some of the elements that govern multisensory processing are the temporal and spatial aspects (two signals should happen at the same time and come from the same location), semantic congruency (sensory information should share the same identity-this happens for both contexts and objects), and cross-modal or synesthetic correspondences (information should be cross-sensory compatible). These factors act in conjunction during perception and considering them might guide the process of multisensory and, by implication, mulsemedia design.

2.3.1 Semantic Congruency. Semantic congruency is one of the factors that underlies the integration effect and refers to situations where the identity and/or meaning of pairs of stimuli match 
Table 1. Cross-Modal Correspondences between Different Sensory Dimensions

\begin{tabular}{|c|c|c|c|c|c|c|c|}
\hline & \multicolumn{3}{|c|}{ Sound } & \multicolumn{2}{|c|}{ Sight } & \multicolumn{2}{|c|}{ Touch } \\
\hline & Pitch & Timbre & $\begin{array}{l}\text { Spectral } \\
\text { Balance }\end{array}$ & Shape & Color & Temperature & Softness \\
\hline Smell & $\begin{array}{c}\text { high-fruity } \\
{[31,182]}\end{array}$ & $\begin{array}{c}\text { piano-fruity } \\
\text { [31] }\end{array}$ & $\mathrm{n} / \mathrm{a}$ & $\begin{array}{c}\text { angular-lemon } \\
{[69]}\end{array}$ & paired [110] & $\begin{array}{l}\text { warm- } \\
\text { cinnamon } \\
{[69]}\end{array}$ & $\begin{array}{c}\text { soft-lemon } \\
\text { [37] }\end{array}$ \\
\hline Taste & $\begin{array}{c}\text { low-bitter, } \\
\text { high-sour, } \\
\text { staccato-salty [66, } \\
120]\end{array}$ & $\begin{array}{c}\text { trombone-bitter, } \\
\text { piano-sweet } \\
{[10,28-30]}\end{array}$ & $\begin{array}{c}\text { low- } \\
\text { sweet } \\
\text { high-sour } \\
{[14]}\end{array}$ & $\begin{array}{c}\text { symmetry- } \\
\text { sweet, pleasant } \\
\text { [202] angular- } \\
\text { bitterness } \\
{[40]}\end{array}$ & $\begin{array}{c}\text { pink-sweet, } \\
\text { white-salty } \\
\text { green-sour, } \\
\text { black-bitter } \\
\text { [188] }\end{array}$ & $\mathrm{n} / \mathrm{a}$ & $\begin{array}{l}\text { rough- } \\
\text { sour } \\
{[184]}\end{array}$ \\
\hline Touch & $\begin{array}{c}\text { variation-direction } \\
\text { [38], high-cold } \\
\text { water [212] }\end{array}$ & $\mathrm{n} / \mathrm{a}$ & $\mathrm{n} / \mathrm{a}$ & $\mathrm{n} / \mathrm{a}$ & $\begin{array}{c}\text { light } \\
\text { color-soft } \\
\text { smooth, } \\
\text { thin, light } \\
\text { [213] }\end{array}$ & $\mathrm{n} / \mathrm{a}$ & $\mathrm{n} / \mathrm{a}$ \\
\hline
\end{tabular}

or mismatch. In the presence of redundant sensory information, their integration can increase signal strength and reliability, and thus semantic congruency becomes a critical factor in multisensory behavioral performance. Semantic congruency was shown to increase visual attention through both spatial and object-based interactions in a visual search paradigm presented in [84], where participants found a cat in a masked image faster when hearing a meow sound. Positive affective effects when using semantic congruent stimuli were illustrated in olfactory-audio or olfactoryvisual combinations in [55, 178, 185]. In [178], participants were exposed to a scent (e.g., odor of an orange) while they were asked to explore a picture containing a corresponding odor-related visual cue (e.g., image of an orange) embedded among other objects. The results showed that the odor-related visual cue was explored faster and for a shorter time in the presence of the congruent odor, highlighting that olfaction can affect visual processing by capturing people's attention. Similar results were found in the case of an information recall task or of a word search game when cue-related odors were emitted $[3,56]$. Another study, where associations between the odorants and motion directions were arbitrarily established by means of classical Pavlovian conditioning, consolidated the functional linking between the olfactory information processing and the visual information processing [97]. Castiello et al. [19] showed the effects of olfactory information on the process of selection for the control of a goal-directed action illustrated by the task of grasping. The authors administered an odor of an object requiring a hand aperture similar in size to (congruent) or different in size from (incongruent) the one of a certain visual target and demonstrated that the size of the object evoked by the smell influenced the subsequent grasping kinematics. These findings show that in a sensorium dominated by vision and audition, olfaction influences perception and cognition in adults and opens up new interaction possibilities.

2.3.2 Synesthetic Congruency. Multisensory binding is enhanced also when cross-modally congruent stimuli are presented [186]. Synesthetic congruency refers to correspondences between basic stimuli features (e.g., pitch, timbre, shape, color) in different modalities. Cross-modal correspondences were shown to influence people's performance under different experimental paradigms: direct cross-modal matching, faster classification tasks, faster simple detection tasks, Implicit Association Tests, spatial localization tasks, and perceptual discrimination tasks [186]. In Table 1, we summarize a set of cross-modal correspondences that have been shown to influence participants' performance. Cross-modal correspondences were demonstrated between various pairs of stimuli: pitch was shown to change the perception on different gustatory dimensions (high pitch 
was matched with sweet/sour taste, while low pitch was matched with bitter taste [10, 29, 30]). High pitch was associated also with fruity smells [31,182] and in the haptic dimension with cold water [212]. Table 1 presents the pairs of stimuli that have a positive effect on performance and that should be considered in any mulsemedia design process.

2.3.3 Congruences and $\mathrm{HCl}$. Semantic and cross-modal mappings have great potential in the design of meaningful computer interfaces and interaction methods. This is because they support comprehension and retention of information through the accommodation of users' sensorimotor skills. Moreover, computer interfaces that explore the usage of cross-modal effects and correspondences have the potential to be more effective and to increase immersion. Promising applications were illustrated in [43], where the authors explore the efficiency of olfaction in introducing a new semantic layer into interaction design and HCI. The study analyzed different mappings between driving-relevant messages and scents and proposed ways of using olfactory simulation to transfer specific information to the user, based on the congruence between visual and olfactory information. Strong associations were found between the "Slow down" message and the scent of lemon, the "Fill gas" message and the scent of peppermint, and the "Passing by a point of interest" message and the scent of rose. In [198], the authors explored the cross-modal correspondences between haptic and audio output through "atmoSphere," a sphere that provides haptic feedback designed to augment focus during mindfulness training by guiding the users into a particular rhythm of breathing.

Because all our senses interact to influence our experiences, different types of sensory cues can be used to guide or modify sensory expectations, search, and augmentation. Since some of our senses currently have a limited use in designing experiences (e.g., taste is currently explored via digitally controlled electric or thermal sensations), there is also potential in designing applications, built on top of cross-modal mappings, that target the user's flavor expectation. For instance, extrinsic cues of flavor can be augmented based on the cross-modal correspondence between roundness and sweetness [207] or between musical articulation and the four basic taste groups [66]. Thus, data can be encoded with relevant parameters that can be perceived as synonymous in different sensory modalities. Inspired by findings from research on cross-modal perception, technology was used to augment the way we experience the flavor in a variety of applications. Visual-taste cross-modal stimuli were used in a mixed reality installation where a colored animated shape was projected on yogurt, changing its taste [15], or in a study that proposes an augmented reality system that changes the flavor of chips through increasing the chroma of a plate [143]. Cross-modal correspondences can be exploited by interactive systems to reinforce or improve different sensory perceptions. Thus, we suggest that cross-modal correspondences could play an important role in designing $\mathrm{HCI}$ from research to more commercial settings.

Sensory Substitution Devices (SSDs) are most of the time complicated to use, since they require intensive training. Cross-modal correspondences could be useful in designing such devices that semantically translate cues of a specific type (e.g., visual information: brightness, shape) into another dimension (e.g., audio information: pitch, loudness). Thus, a more efficient alternative to existing SSDs could be to engage the sensory substitution via multiple sensory channels using different cross-modal mappings. As a result, the process becomes more intuitive, training time is shortened, and the participant performance is improved [192]. Encouraging results were found for color-to-sound [67], tactile-to-sight [16], and sounds-to-smell substitutions [26].

\section{PRODUCTION, DISTRIBUTION, AND RENDERING IN MULSEMEDIA SYSTEMS}

Mulsemedia systems are usually obtained by adding feedback to a visual and/or audio stream, which triggers other sensorial channels (e.g., haptic, olfactory, gustatory). This process consists of three stages: (1) production, (2) distribution, and (3) rendering. In [34], the authors propose a 


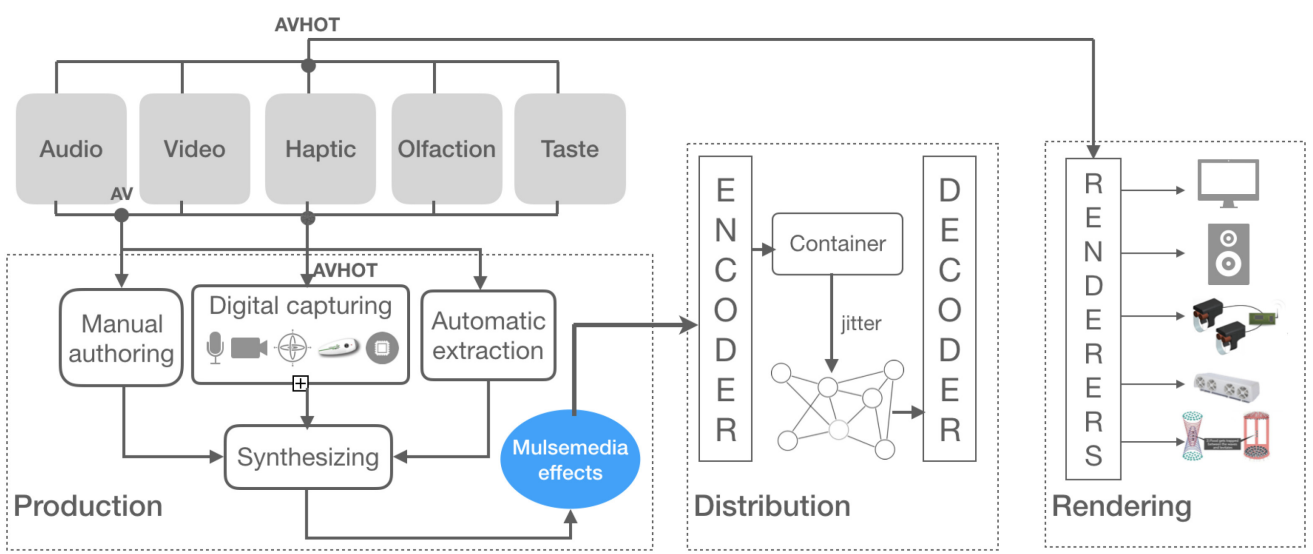

Fig. 2. Production-distribution-rendering workflow for creating multisensory systems. AV = Audio Video, AVHOT = Audio Video Haptic Olfaction Taste.

workflow for adding haptic feedback to audiovisual (AV) content. In this section, we extend this workflow with details regarding production and rendering of systems that also stimulate the chemical senses (taste and smell), as illustrated in Figure 2. Accordingly, production deals with how different sensory effects can be created or generated in synchronization with the AV content. Multisensory effects can be produced through different techniques: digital capturing and processing of data acquired from sensors, automatic extraction from video or AV content, or manual authoring of mulsemedia effects. Once the mulsemedia effects are captured, they are encoded for transport, processed, and then emitted for distribution to providers, distributed to the end-users, and then decoded, so that the mulsemedia effects can be rendered by different devices and experienced by the end-users. In order to be effective, mulsemedia effects have to be synchronized temporally.

Since [35] provides an extensive overview of the haptic audio visual (HAV) aspects, in this section we will focus on new research in the haptic area and on the addition of chemical sensory modalities, which differ in the production/rendering mechanism from the physical ones.

While we understand sight, hearing, and touch well enough to build machines to mimic them, we know less about the chemical basis of taste and smell. Cameras are electronic eyes, mechanical resonators transmute sounds into signals our brain recognizes, and touch is a pressure sensor, but smell and taste are subtle senses, complex mixtures of different molecules. Both sensing and actuation of smells are hard to realize because of their organic nature. Thus, despite their influence on human behavior and the interesting possibilities they raise (for instance, we have stereo smell and can distinguish the origin vector of a scent to approximately 10 degrees of acuity [209]), there is a surprisingly paucity of use of scent and taste in VR, HCI techniques, and mulsemedia. In the following subsections, we will offer informative insights that extend the ad hoc knowledge about mulsemedia design into a formal framework. We expect that academia or industry practitioners who are not experts in mulsemedia design will have a starting point that will allow them to accelerate the generation of multisensory tools, techniques, and test scenarios.

\subsection{Production}

Although most human-technology interactions are still based on traditional desktop/mobile interfaces that involve primarily the visual and audio senses, in recent years we have witnessed progress in multisensory experiences involving haptics. Though much development is needed, 


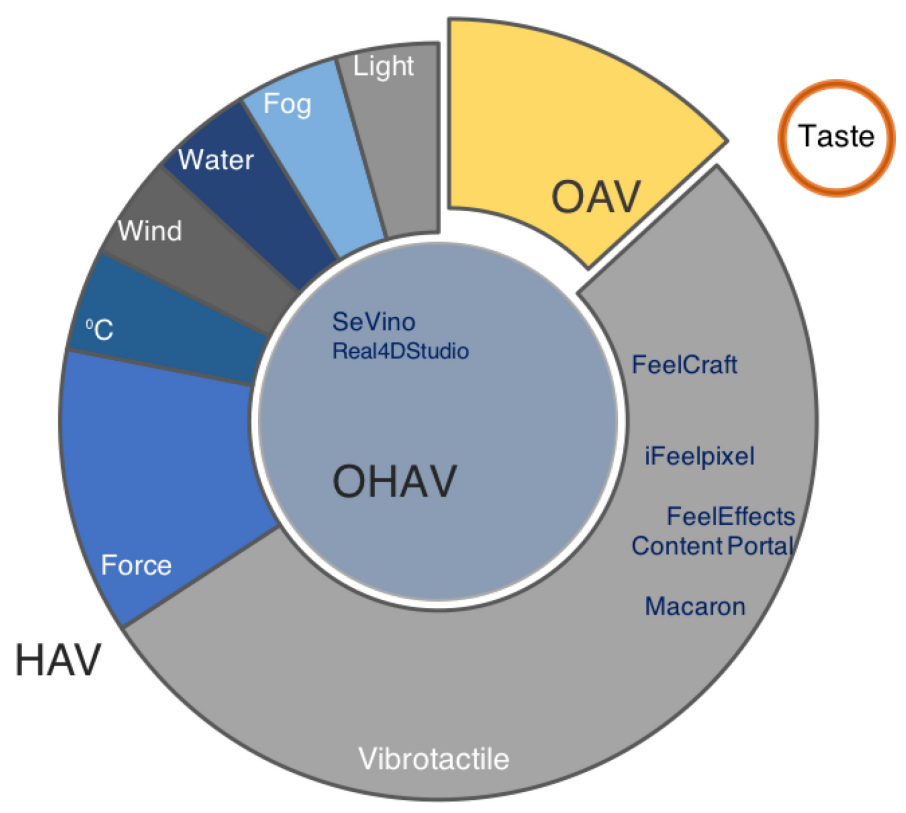

Fig. 3. A histogram of different existing "sense" editors. Haptic audio video (HAV) editors are the most popular with several open-source tools. Olfaction haptic audio video (OHAV) editors are less represented. Olfaction audio video (OAV) and audio video tools enhanced with temperature, light, fog, wind, water, light, and force are mostly experimental, while taste editors are not yet implemented.

the perspective is that the senses we use in our interactions with technology will not be restricted and we will be able to create richer experiences.

Notwithstanding the fact that audio and video content can be easily produced with a variety of tools and methods, development of new interaction methodologies and the use of new interaction devices are more problematic since they involve the rapid prototyping of user interfaces [152]. Designers still manually create effects using in-house authorization tools in an event trigger scheme, resulting in a labor-intensive work. Moreover, often, guiding principles for creating such effects that are associated to the content watched, heard, or read are missing [87]. Commercial companies like D-Box ${ }^{3}$ or CJ 4 Dplex $^{4}$ create haptic effects using proprietary tools, but they do not make available the lessons from their releases. Even if this technique does not require a change in the current media production process, a better placement of effects should be provided when a designer has the possibility to tune the result with authoring tools.

In this subsection, we will focus on how to create content that addresses various sensory channels (visual, auditory, haptic, olfactory, gustatory) in order to produce new body experiences through novel types of interactions. We will present libraries that could be used along with MPEGV-based protocols and editing tools for different types of sensory effects to be rendered with the AV stream. In order to offer an overview of the existing software-based editing tools that could be used to accelerate the prototyping of mulsemedia systems and the exploration of mulsemedia design, we looked at different solutions provided by the literature. In Figure 3, we illustrate the repartition of these editors based on the targeted sense. We found that existing collections of sensory

\footnotetext{
${ }^{3}$ D-Box: http://www.d-box.com/.

${ }^{4}$ CJ 4Dplex: http://www.cj4dx.com/.
} 
Table 2. Multisensory Editors Based on Direct Signal Graphical Representation

\begin{tabular}{|c|c|c|c|c|c|}
\hline $\begin{array}{l}\text { Data } \\
\text { Format }\end{array}$ & Effects & Tools & Type & About & Users \\
\hline \multirow{3}{*}{$\sum_{x}^{\mid}$} & $\begin{array}{l}\text { Audio, Video, } \\
\text { Vibrotactile }\end{array}$ & posVibEditor [166] & $\begin{array}{l}\text { Standalone - } \\
\text { edit and play }\end{array}$ & $\begin{array}{l}\text { Drag-and-drop design paradigms. } \\
\text { waveform editing, multichannel } \\
\text { support for multiple actuators } \\
\text { placed on body sites. Suitable for } \\
\text { mobile devices and virtual reality } \\
\text { applications. }\end{array}$ & Gen. \\
\hline & $\begin{array}{l}\text { 3D shapes, } \\
\text { Vibrotactile }\end{array}$ & VITAKI [112] & $\begin{array}{l}\text { Standalone } \\
\text { (C++ API) - } \\
\text { device } \\
\text { independent }\end{array}$ & $\begin{array}{l}\text { Waveform editing, prototyping } \\
\text { platform for decoding } \\
\text { vibrotactile feedback (i.e., Morse } \\
\text { signals) on the haptic gloves } \\
\text { driven by Eccentric Rotating } \\
\text { Mass (ERM) motors (e.g., object } \\
\text { fall detection in VR gaming). }\end{array}$ & Dev. \\
\hline & $\begin{array}{l}\text { Audio, } \\
\text { Vibrotactile }\end{array}$ & $\begin{array}{l}\text { Beadbox [138]; } \\
\text { Emoti-Chair [89] }\end{array}$ & Standalone & $\begin{array}{l}\text { Timeline editing, interface design } \\
\text { with “Bead" based on sensory } \\
\text { substitution models } \\
\text { (color-frequency). }\end{array}$ & Art. \\
\hline \multirow{6}{*}{ 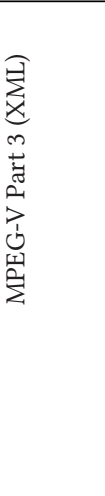 } & \multirow{4}{*}{$\begin{array}{l}\text { Audio, Video, } \\
\text { Vibrotactile, } \\
\text { Wind, Water, } \\
\text { Temperature, } \\
\text { Light, Fog, } \\
\text { Scent }\end{array}$} & $\operatorname{SeVino}^{a}[211]$ & $\begin{array}{l}\text { Standalone, } \\
\text { web service }\end{array}$ & \multirow{4}{*}{$\begin{array}{l}\text { Tool chain for video annotation } \\
\text { and synchronization of different } \\
\text { effects - device independent } \\
\text { (writes MPEG-V-based SEM and } \\
\text { performs 3D simulation). }\end{array}$} & Dev. \\
\hline & & $\begin{array}{l}\text { Real4DStudio }^{b}- \\
\text { authoring tool }\end{array}$ & Standalone & & Gen. \\
\hline & & $\begin{array}{l}\text { SMURF (extension of } \\
\text { SeVino) [92] }\end{array}$ & Web service & & Dev. \\
\hline & & RoSE studio [24] & Framework & & Gen. \\
\hline & \multirow{2}{*}{$\begin{array}{l}\text { Audio, Video, } \\
\text { Vibrotactile, } \\
\text { Wind, Force }\end{array}$} & $\begin{array}{l}\text { H-Studio authoring } \\
\text { tool [34], PlaySEM } \\
\text { [169] }\end{array}$ & Standalone & $\begin{array}{l}\text { Edition of motion effects and } \\
\text { synchronization with } \mathrm{AV} \text { content. }\end{array}$ & Dev. \\
\hline & & $\begin{array}{l}\text { Web haptic player } \\
{[44]}\end{array}$ & Web service & $\begin{array}{l}\text { Import 3D models and add haptic } \\
\text { properties - haptic device } \\
\text { independent. }\end{array}$ & Gen. \\
\hline 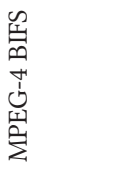 & $\begin{array}{l}\text { Audio, Video, } \\
\text { Vibrotactile, } \\
\text { Force }\end{array}$ & $\begin{array}{l}\text { Authoring } \\
\text { framework for haptic } \\
\text { broadcasting [20][93] }\end{array}$ & Framework & Passive haptic interactions. & Dev. \\
\hline 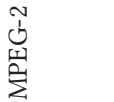 & Video, Scent & $\begin{array}{l}\text { Smell video system } \\
{[196]}\end{array}$ & Standalone & $\begin{array}{l}\text { Image processing and text } \\
\text { analysis to extract smells and } \\
\text { authoring tool. }\end{array}$ & Dev. \\
\hline
\end{tabular}

Note: Gen. - General area; Dev. - Development; Art. - Artists.

${ }^{a}$ SeVino: http://selab.itec.aau.at/software-and-services/.

${ }^{b}$ Real4Dstudio: http://cast.real4dhub.or.kr/about/authoring/download.

sensations and programming toolkits are focused mostly on haptic effects (especially vibrotactile (VT) stimuli) [20, 86, 87, 92, 93, 104, 112, 152, 166, 173-175, 177, 197], while the olfaction field remains insufficiently explored $[24,92,196,211]$ and there is no tool for editing gustatory effects. These tools are presented in more detail in Table 2, Table 3, and Table 4, respectively.

3.1.1 Production of AV Stream. Visual content has evolved from traditional 2D videos to stereoscopic 3D panoramic images. However, 3D content is often expensive to produce. 2D-to-3D conversion techniques have the potential to make the process faster, and several approaches have 
Table 3. Metaphor-Based Multisensory Editors

\begin{tabular}{|c|c|c|c|c|c|}
\hline $\begin{array}{l}\text { Data } \\
\text { Format }\end{array}$ & Effects & Tools & Type & About & Users \\
\hline \multirow{2}{*}{ 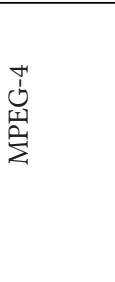 } & \multirow[b]{2}{*}{$\begin{array}{l}\text { Video, Audio, } \\
\text { Vibrotactile }\end{array}$} & $\begin{array}{l}\text { Tactile movie } \\
\text { authoring [93] }\end{array}$ & Standalone & $\begin{array}{l}\text { Visual media metaphor (first, third } \\
\text { person and background effect) for } \\
\text { tactile authoring. }\end{array}$ & Dev. \\
\hline & & TactiPEd [152] & Standalone & $\begin{array}{l}\text { Actuator sequencing metaphor for } \\
\text { visualization and adjustment of } \\
\text { amplitude, frequency, and } \\
\text { sequence duration (separate } \\
\text { control of each actuator). }\end{array}$ & Dev. \\
\hline \multirow{2}{*}{$\sum_{\dot{x}}^{\ominus}$} & $\begin{array}{l}\text { Audio, } \\
\text { Vibrotactile }\end{array}$ & $\begin{array}{l}\text { VibScoreEditor } \\
\text { [104] }\end{array}$ & & $\begin{array}{l}\text { Score-based editing using the } \\
\text { musical score and VT clef } \\
\text { metaphors. }\end{array}$ & Dev. \\
\hline & $\begin{array}{l}\text { Video, } \\
\text { Vibrotactile }\end{array}$ & Mango [174] & & $\begin{array}{l}\text { Animation metaphor that allows } \\
\text { the manipulation of vibrotactile } \\
\text { sensations continuously in space } \\
\text { and time. }\end{array}$ & PA. \\
\hline
\end{tabular}

Note: Gen. - General area; Dev. - Development; Art. - Artists; PA. - Professional Animators.

been proposed for this: manual, human assisted, and automatic conversion. Moreover, 3D visual information also can be produced using capturing devices like 3D cameras and 3D scanners [151]. Mobile phones and tablets can be used for stereo-based depth measurement, opening up new possibilities for 3D reconstruction [94]. 3D printers started to be used to provide a tactile dimension to traditional visual representations: for cosmic representations [25] or for visualizing anatomy [1].

Sound had until recently a marginal role in the design of virtual environments or mulsemedia systems. With the development of VR, immersive audio became something crucial because it needs to match up 3D visuals that convey an enhanced sense of realism. Recent research started to evaluate the influence of using 3D sound in improving performance or spatial localization in VR systems, showing that it enhances the immersion level of players [23, 144]. Binaural recording systems are a specific approach of the stereo recording where two microphones are located in place of the two ears on an artificial head [95]. Binauralization engines that utilize Head-Related Transfer Functions (HRTFs) are available from plugins such as 3DCeption from Two Big Ears, ${ }^{5}$ which captures interaural level and time differences as well as spectral cues. 3DCeption ensures that the audio is synchronized with the video, regardless of the playback mechanism, and ensures all kinds of audio: mono, stereo, multichannel, and ambisonics across platforms and devices.

3.1.2 Production of Haptic Effects. In this article, we use the HCI definition for haptic that involves one or more perceived sensations of touch (tactile and proprioceptive feedback, active human touch, and passive experience of actuated technology).

Haptic effects occur within a scene with the aim to augment the user's presence, to enhance ambiance or emotion, or for training purposes. A comprehensive classification of the types of haptic effects that can be used in multisensorial systems is presented in [210]. They include temperature, water sprayer, air-flow, whole-body vibration, passive kinesthetic motion and force, active kinesthetic, tactile, and rigid body. Haptic feedback can be produced in free space in several ways: through conventional direct-contact wearable devices (e.g., gloves [109], haptic vest [106], manipulation of the location of the actuators [171]) or contactless haptic feedback through air-jet or ultrasonic radiation pressure [7].

\footnotetext{
${ }^{5}$ Two Big Ears and 3Dception: http://twobigears.com/spatworks/index.html\#features.
} 
Table 4. Multisensory Editors Based on Libraries and Databases

\begin{tabular}{|c|c|c|c|c|c|}
\hline $\begin{array}{l}\text { Data } \\
\text { Format }\end{array}$ & Effects & Tools & Type & About & Users \\
\hline \multirow{6}{*}{ Libraries } & \multirow{4}{*}{ Vibrotactile } & VibViz [177] & \multirow{2}{*}{ Standalone } & $\begin{array}{l}\text { 120-item VT library (annotated by } 5 \\
\text { taxonomies: physical, sensory, } \\
\text { emotional, usage examples, metaphor). }\end{array}$ & Dev. \\
\hline & & $\begin{array}{l}\text { FeelEffects [87] } \\
\text { and FeelCraft } \\
\text { plugin }^{a}[173]\end{array}$ & & $\begin{array}{l}\text { 50-item VT library ( } 6 \text { types of } \\
\text { metaphors: rain, travel, etc.). }\end{array}$ & Gen. \\
\hline & & Macaron $^{b}[175]$ & $\begin{array}{l}\text { Web } \\
\text { service }\end{array}$ & $\begin{array}{l}\text { Open-source interactive design editor } \\
\text { that facilitates remixes of existing } \\
\text { vibrations. }\end{array}$ & Gen. \\
\hline & & $\begin{array}{l}\text { Feel Messenger } \\
{[86]}\end{array}$ & $\begin{array}{l}\text { Standalone } \\
\text { (Android) }\end{array}$ & $\begin{array}{l}\text { Communication API, haptic } \\
\text { vocabulary (haptic patterns stored as } \\
\text { feelgits with preset parameters - } \\
\text { feelbits), and interface for receiving } \\
\text { and authoring haptic messages. }\end{array}$ & Gen. \\
\hline & $\begin{array}{l}\text { Vibrotactile, } \\
\text { Force }\end{array}$ & $\begin{array}{l}\text { TouchSense } \\
\text { SDK }^{c} \text { (Android), } \\
\text { ViviTouch } \\
\text { Studio [197] }\end{array}$ & $\begin{array}{l}\text { Standalone/ } \\
\text { plugin }\end{array}$ & $\begin{array}{l}\text { Haptic prototyping alongside video } \\
\text { and audio (pause, seek, mute, } \\
\text { synchronize effects). }\end{array}$ & Gen. \\
\hline & $\begin{array}{l}\text { Vibrotactile, } \\
\text { Force, } \\
\text { Audio }\end{array}$ & iFeelpixel $^{d}$ & Standalone & $\begin{array}{l}\text { Enables users to interact with the } \\
\text { computer GUI using vision, touch, and } \\
\text { hearing and allows them to mediate } \\
\text { graphic structures. }\end{array}$ & Gen. \\
\hline \multirow[b]{2}{*}{ Databases } & \multirow[b]{2}{*}{$\begin{array}{l}\text { Video, } \\
\text { Audio, } \\
\text { Vibrotactile }\end{array}$} & Content Portal ${ }^{e}$ & \multirow[b]{2}{*}{$\begin{array}{l}\text { Standalone } \\
\text { (Android, } \\
\text { iOS) }\end{array}$} & $\begin{array}{l}\text { Showcase of video, media, and games } \\
\text { enhanced with tactile effects. }\end{array}$ & Gen. \\
\hline & & $\begin{array}{l}\text { Demonstration- } \\
\text { based editor [80], } \\
\text { Apple's vibration } \\
\text { editor (only } \\
\text { binary on/off } \\
\text { information) }\end{array}$ & & $\begin{array}{l}\text { Generates a VT pattern by imitating } \\
\text { the touch input pattern of the user. }\end{array}$ & Gen. \\
\hline
\end{tabular}

Note: Gen. - General area; Dev. - Development; Art. - Artists; PA. - Professional Animators.

${ }^{a}$ FeelCraft: https://github.com/Litarvan/Feelcraft.

${ }^{b}$ Macaron: https://www.cs.ubc.ca/labs/spin/macaron.

${ }^{c}$ TouchSense SDK: https://www.immersion.com/products-services/touchsense-sdk-mobile-apps/.

$d_{\text {iFeelpixel: http://www.ifeelpixel.com/download/. }}$

${ }^{e}$ Content Portal: https://play.google.com/store/apps/details?id=com.immersion.tsengageportal\&hl=en.

Haptic technology can produce stimuli to feel in diverse ways, the most common approach being the vibrotactile (VT) feedback. VT arrays (gaming chairs or tactile vests [158]) are a haptic technology that uses parametric models of sensory illusions to render moving haptic patterns. In fact, VT signals exist in many everyday devices, and a study presented in [176] confirms users' interest in customizing these effects. However, despite this potential and the rise of new haptic interfaces, there is still a gap between haptics and mainstream communication caused by the lack of haptic authoring tools, the production infrastructure, the standardized playback protocol, or the design of engaging, understandable effects. The design of intuitive and effective VT cues requires multiple development iterations and user evaluations. Haptic technology, already used to create immersive user experiences in VR or video games, seems to display a great potential to also enhance user experiences in mulsemedia [111]. However, mainstream media does not yet use the richness of the haptic modality because of the lack of haptic authoring tools, standardized playback protocols, and trained workers. 
Haptic feedback is mostly manually customized through dedicated editors with effects created during the postproduction phase. Haptic information can also be produced through data acquired and processed directly from the sensors, or through automatic extraction from AV content or from metadata [168] (e.g., effects from a football game displayed with a vibrating device [203]). For instance, activity in a video feed [90] can be mapped to haptic transducers that are arranged along a chair; movements from the visual scene are thus mapped with events from 4D movies or rides. Similarly, sound can also be used to extract haptic cues for music or video gaming.

In embedding haptic information in media, designers need to have access to haptic effects tools and libraries that enable rapid prototyping and easy authoring. As seen in Figure 3, haptic editors are favored over authoring tools for other senses. Several interfaces that support different types of devices are currently available. Some of them are based on direct representation of the vibration signal as editable waveforms [152]. The Hapticon Editor [48] is used for creation and editing of haptic icons for a 1-DOF ${ }^{6}$ force feedback device. VT icons can be prototyped with posVibEditor[166] that also supports the creation of a library of patterns using XML-based pattern files. Other editors also support media augmentation through the predefinition of a library of haptic patterns. The Touch Effects Studio (Immersion Corporation) and Vivitouch Studio [197] are focused on devices with either a temporal or spatial component through tools for enhancing video and audio with effects from a library of haptic icons. Schneider, Israr, and MacLean in [174] introduced the tactile animation metaphor and proposed Mango to allow users to efficiently create dynamic 2D haptic patterns, associate them to multimedia, and apply them to a variety of devices. Other editors are built for authoring haptic content using accessible touchscreen interactions. Simplistic patterns that allow users to control only the vibration duration can be created using Apple's vibration editor (since iOS 5). Moreover, in [79], Apple's approach was extended on an Android platform to support a complex vibration waveform design in an intuitive way (sequence of taps and drags).

3.1.3 Production of Chemical Effects (Olfactory and Gustatory). Unlike the other senses, smell and taste are complicated processes that result from the biomechanical reaction between human receptor(s) and a binding site on a molecule. In fact, an aroma is not identified due to one single molecule, but due to the interaction of many molecules and biochemical reactions. Although there are many challenges related to studying taste and smell, no other sensory modality is as emotionally potent as olfaction [148]. It has been shown that smell reinforced the way a viewer enjoys an artwork [101] or that smell and taste have the potential to facilitate the acquisition of new knowledge based on previous experiences in education [73]. With the advance of technology and the understanding achieved in psychology and neuroscience, researchers started to shape the development of technologies based on smell and taste [141]. "Virtual Cocoon" is a helmet that addresses all five senses: hearing, sight, and touch senses are stimulated digitally, while taste and smell are stimulated analogically by chemicals emitted by the helmet [21]. This analog solution, applied for chemical senses, has several drawbacks related to its manageability and scalability.

Taste. There are five basic tastes: sweet, salty, bitter, sour, and umami [36]. When we taste any food or beverage, we perceive each type of taste as a qualitative data analyzed by our brain indicating effects on the sensory organs called taste buds. Within HCI, taste stimulation is mainly achieved through the use of chemical stimulation or through electrical and/or thermal stimulation of the user's tongue. This invasive nature of taste and the fact that taste-based experiences are volatile represent important hurdles for HCI researchers [125].

${ }^{6} \mathrm{DOF}=$ degrees of freedom 
Traditionally, users experience taste through chemical components (liquid or solid form): glucose (sweet), citric acid (sour), caffeine/quinine (bitter), sodium chloride (salty), and monosodium glutamate (unami) [146]. This approach has been used in [116], where the author proposed the new paradigm of Edible User Interfaces and evaluated its effectiveness in an HCI context. The "painted bits" of a computer monitor are replaced by tangible "edible bits," with potential applications for network monitoring and profiling. This paradigm is used also for "Taste Screen," which consists of small transparent cartridges that are placed on the screen and release a flavoring agent when users lick it [116]. In [125], the researchers proposed an example of a gustatory interface called "LLOLio," an interactive lollipop that changes its taste. The authors focused on the sweet taste of the lollipop in combination with sour liquid to deliver a taste and haptic input modality. Results showed that gustatory games could benefit from the interaction between sweet and sour. While the chemical approach is less invasive than the electrical and thermal simulation of the tongue, it requires the continuous preparation of the taste stimuli that are difficult to store and manipulate. Moreover, the chemical stimulation is analogous, and thus impractical for digital interactions.

Taste qualities can be perceived also by stimulating the tongue papillae through thermal or electrical or stimulation. Sweet sensation was shown to be produced by warming the anterior (front) edge of the tongue, while the sourness and saltiness were created through the cooling of the tongue in [32]. Sweet, sour, and bitter tastes were stimulated electrically by placing a silver wire on the tip of the tongue and a reference electrode on the left wrist of the subject in [156]. In [160], a team from the University of Singapore presented a device with a $2 \times 2$ grid of peltier elements that deliver heating and cooling stimuli to the tongue, simulating the sensation of sweetness. Using this approach, the team proposed a "Vocktail" (Virtual Cocktail) that utilizes three sensory modalities (taste, smell, and visual-color) to create virtual flavors [162] and a "Digital lollipop" that digitally simulated the sour sensation on the human tongue at three intensity levels. In [170], the authors presented a taste interface for future meaningful Internet multisensory communication through the digital actuation of sweet sensations. They created the sweet taste by manipulating the temperature on the tongue. Texture, another important factor in the eating experience, was simulated through the Electric Food Texture System presented in [142]. This device, placed on the masseter muscle, can not only mimic the texture but also modify the texture of real food, and its creators are contemplating combining it with chewing sounds. An advantage of the electrical/thermal approaches is that they allow for more control and replication of taste stimuli over a long period of time and over distance (e.g., Taste/IP [159]). Currently, nonchemical taste stimulation methods are the least explored in interactive systems.

Another approach consists of pseudo-gustatory displays based on the virtual color of a real drink [140]. "MetaCookie" is a system that creates customized tastes of the same cookie by dispensing different scents to users' noses with the motivation to investigate cross-modal effects of visual feedback and the interpretation of the flavor. "Affective Tumbler" uses the same cross-modal principles and applies thermal sensations on the skin to stimulate skin temperature changes [195]. In [208], the authors highlight through "TasteBud" how the complete spectrum of five basic tastes can be employed and propose a novel and innovative delivery mechanism that uses acoustic levitation"TastyFloats." "Virtual Lemonade" introduces a new method and a digital platform for sharing lemonade using cross-modal principles that consists of sensing (RGB color and $\mathrm{pH}$ value are captured), distribution (the XML protocol to encode the data), and stimulation through a tumbler that overlays color over the beverage and stimulates the tongue using electric impulses [161].

Commercially, Planet Licker ${ }^{7}$ is a first step toward incorporating taste into game play by licking flavored ice pops on a USB-connected controller.

$\overline{{ }^{7} \text { Planet Licker: http://a-o.in/games/pl/. }}$ 
Smell. Natural odor molecules with the exception of a few molecules like hydrogen sulphide are small carbon-based entities that float into the air and form an invisible plume of odor. Although it is not clear how we detect molecules, there are some theories about this process. One idea refers to the "vibrational modes" of an odorant that are its signature [54]. This study suggests that an odor molecule can be seen as a collection of atoms on springs. The quantum effect causes the spring to vibrate and thus the molecule to be identified.

Smell in an environment can be captured manually by sucking the air across an automated thermal desorption tube. The odor molecules stick to the fine granular material in the tube. These molecules can be determined after they are separated by a gas-liquid chromatography instrument. A mass spectrometer then produces a histogram of the present molecules [63]. Olfactory information can be produced through a system consisting of an electronic nose or an odor recorder. The classical electronic nose is based on an array of sensors that provides a pattern of a diagnostic given odor. Classical electronic noses utilize an array of chemical sensors of different specificities that respond to volatile compounds present in gases. This array of chemical sensors is coupled with a pattern recognition mechanism that allows the identification of complex smells [220]. The electronic nose can be used for olfactory recording if combined with a smell reproducing technique [133]. In [132], the authors present an odor recorder for dynamic changes in an environment, and in [214], the authors proposed a method to record odors that consists of many components. In addition to the classical sensor-array-based approach, electronic noses based on other technologies have also been exploited. There are examples where mass and ion mobility spectrometers or flash gas chromatographs are used to detect the components of a gas mixture. Electronic noses have been successfully used in cancer diagnosis [107] or in the food industry [51]. However, in spite of having different approaches and thus providing different input, the limits of electronic nose technology resulting from the fundamental sensing components are obvious [167]. Commercially, $\mathrm{NeOse} e^{8} \mathrm{com}-$ bines different technologies to directly analyze and quantify volatile organic compounds and tests them against a database of known smells. NeOse allows companies to record their own scents in the database and has as main targets the food and cosmetic industries, but it can also test air quality.

Despite these attempts in developing gustatory and olfactory input devices, the main focus of the digital olfaction community in mulsemedia has been nonetheless on olfactory output modalities through studies on timing and multimedia processing [57, 129].

3.1.4 Creating Multisensory Content; Ready-Made Libraries and Editors. As shown, multisensory feedback has the potential to convey meaningful information to users. However, despite the availability of a broad range of technologies, there are no guiding principles for associating multisensory feedback with AV content. Therefore, different types of tools should be provided to a designer who wants to create engaging experiences; to meaningfully harness touch, smell, and taste in mulsemedia interaction; to determine the meaningful design space for multisensory interactive experiences; to study and understand different sensory modalities along with their cross-sensory associations; and so forth. Using a framework or a library that includes fine-grained descriptions with their experiential correlates can speed up the design process [148]. While the libraries of effects might still be useful for end-user customization, they do not support the capability for deconstruction and recomposition-they are opaque in construction and immutable. For experts who want access to the source code, an editable model and external examples would be necessary in the design process.

Table 2, Table 3, and Table 4 present different types of multisensory design tools starting from VT libraries and continuing with editors based on variations of MPEG-V format [201] that support

$\overline{{ }^{8} \mathrm{NeOse}: \text { http://aryballe-technologies.com. }}$ 
different types of haptic effects (vibration, temperature, wind, water-spray, motion) as well as scent, shadow, or fog. Some of these editors are track based with a graphical representation to edit waveforms (Table 2), some are based on different types of metaphors (Table 3), some address additional features like mobile interfaces, while others are example-based tools. In Table 4, we present libraries of effects that can be used for keyframe-based behavior editing and refinement. Based on the level of required expertise and on the multisensory channels that need to be stimulated, these tools could be used to make the prototyping process faster.

\subsection{Distribution}

In the mulsemedia content distribution, the formalized sensorial effects are stored, transmitted, and synchronized through authoring tools/platforms (see Tables 2, 3, and 4) over the heterogeneous network environment [35]. In networked systems, there are many concurrent processes making use of the same resources. When simultaneous signals are evoked from more than two sensory modalities, the user's attention is quickly directed toward the source and the Quality of Experience (QoE) is enhanced $[165,216]$. These sensory inputs become coherent through cross-modal integration. As a result, we make better temporal or spatial judgments [12], or we have a richer experience [47] of the event that generated those signals. In mulsemedia systems, sensory inputs are integrated according to the temporal interval between the stimuli [190]. When the real-time data streams are transmitted over a network, the delay jitter disturbs the temporal relationship between the media streams. Moreover, a temporal ordering of sensorial events has to be guaranteed in the mulsemedia synchronization systems [2].

Scant research in the mulsemedia domain has focused on identifying the thresholds that allow different senses to be separated while remaining integrated. The procedure to identify the point where the bond between sensorial channels breaks consists of separating the events in time and space and varying the increments until they are no longer perceived as an entity [42]. These temporal in-sync/out-of-sync boundaries were explored for audio, video, olfactory [57, 131], haptic, and airflow [215] combinations as shown in Table 5, where we present different asynchrony thresholds between media channels.

Media synchronization has been evaluated as the relationship between two types of media streams. The investigation of intermodal asynchrony was initially focused on audiovisual events. In [42], the authors observed that speech and nonspeech stimuli had different thresholds (nonspeech: $\{-75 \mathrm{~ms}, 175 \mathrm{~ms}\}$, speech: $\{-130 \mathrm{~ms}, 250 \mathrm{~ms}\})$. Reinforcing this, [119] proposed a lip-reading task and showed that the performance of users dropped significantly when the soundtrack was delayed by 160ms. In [191], the users' perception evaluations of lip synchronization for audiovisual events showed that the skews could be more easily sensed by users when the video is ahead of the audio, and the "in sync" region of the lip synchronization is $\{-80 \mathrm{~ms}, 80 \mathrm{~ms}\}$.

Recently, additional media streams (e.g., addressing touch) were added as a new dimension to the user experience [169]. Haptic technology has become accessible and started to be used in modern device interfaces like teleoperators (e.g., haptic mouse and grip for video gaming, medical simulation or art design), touchable screens of smartphones and some PCs, and some contactless devices in augmented/VR systems. Haptic applications require high demand of bandwidth to enable the data transmissions over a high reliable and responsive network [183]. In applications like teleoperation, the accuracy of timing between haptic and other media streams is vital for the QoE. Thus, it is significant to consider the network restrictions (i.e., delays, jitter, and losses) in the mulsemedia distributions and to identify the thresholds of interstream synchronization. In [181], a high degree of sensitivity (100ms) in perceiving asynchrony between media channels (HA and HV) has been observed in a multimedia presentation with a haptic reference stream resembling a ping-pong 
Table 5. Quality of Service for Synchronization Purposes

\begin{tabular}{|c|c|c|c|c|}
\hline Media 1 & Media 2 & $\begin{array}{c}\text { Synchronization } \\
\text { Type }\end{array}$ & Application & $\begin{array}{l}\text { Tolerable } \\
\text { Range }\end{array}$ \\
\hline \multirow{8}{*}{ Video } & \multirow{5}{*}{ Scent } & \multirow{2}{*}{$\begin{array}{l}\text { Audio media } \\
\text { dependent [57] }\end{array}$} & $\begin{array}{l}\text { In the absence of audio } \\
\text { media [129] }\end{array}$ & {$[-5 s,+10 s]$} \\
\hline & & & $\begin{array}{l}\text { In the presence of audio } \\
\text { media [4] }\end{array}$ & {$[-30 s,+20 s]$} \\
\hline & & \multirow{3}{*}{$\begin{array}{l}\text { Scent type } \\
\text { dependent [128] }\end{array}$} & Foul scent & {$[0 \mathrm{~s},+15 \mathrm{~s}]$} \\
\hline & & & Spicy, fruity, flowery scents & {$[-10 \mathrm{~s}, 10 \mathrm{~s}]$} \\
\hline & & & Burning scents & {$[-5 \mathrm{~s},+10 \mathrm{~s}]$} \\
\hline & Haptic & Tightly coupled & Gaming Vest [215] & {$[0 \mathrm{~s}, 1 \mathrm{~s}]$} \\
\hline & Airflow & Tightly coupled & Fan [215] & {$[-5 s,+3 s]$} \\
\hline & Taste & Tightly coupled & $\begin{array}{l}\text { Difference between } \\
\text { taste-visual latencies [135] }\end{array}$ & {$[13 \mathrm{~ms}-837 \mathrm{~ms}]$} \\
\hline \multirow[t]{2}{*}{ Haptic } & \multirow[t]{2}{*}{ Scent } & \multirow{2}{*}{$\begin{array}{l}\text { Video media } \\
\text { dependent [83] }\end{array}$} & Good & $\begin{array}{l}{[-1,380 \mathrm{~ms}} \\
-250 \mathrm{~ms}]\end{array}$ \\
\hline & & & Allowable & $\begin{array}{l}{[-1,380 \mathrm{~ms},} \\
400 \mathrm{~ms}]\end{array}$ \\
\hline
\end{tabular}

game. In [199], the authors investigated to what extent QoE is affected by network delay across the transmission of haptic media, audio, and video through a haptic-transferred system.

In this study, a simulated network delay for each media stream has been introduced while monitoring changes in the QoE. The results indicated that Mean Opinion Score (MOS) values are bound up with the differences of network delay jitters among the media streams (i.e., haptics, audio, and videos) [199]. However, the authors did not identify the threshold of perception of asynchrony. In [219], this study was extended with a networked musical ensemble composed out of a tambourine and a keyboard harmonica, with results showing that the interstream synchronization error rate in this situation was decreased against the works in [199]. Interestingly, this asynchrony can be masked in tri-stimuli systems by one of the present sensory modalities (e.g., audio has been shown to mask the synchronization skews in olfaction-enhanced presentations [4]).

Another important aspect of the distribution is supporting high-quality services for mulsemedia in the context where there is an exponential growth in the user population and in the resource requirements of the networked applications.

In [217], the authors propose an adaptive mulsemedia framework (ADAMS) that has been shown to improve user perception and QoE in variable network delivery conditions. Using an MPEG-7 ${ }^{9}$ description scheme compatible with MPEG codecs, ADAMS designs two adaptation schemes on the server side: a flow-based steam-switch adaptation scheme and a mulsemedia-based packet priority scheduling scheme that differentiate the mulsemedia (i.e. haptic, air-flow, and olfaction) and multimedia (i.e., audiovisual) content distribution depending on the available network bandwidth and human preferences.

Network Function Virtualization (NFV) and Software-Defined Networking (SDN) are technologies that provide tools to design networks with a greater degree of abstraction, increasing the network flexibility [5]. SDN architecture decouples network control and data forwarding functions

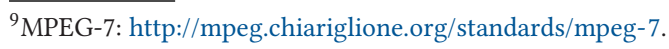


and enables direct programmability by upper-layer applications. SDN paradigms can be used to dynamically allocate network resources to different DASH clients, while an SDN manager would be used to dynamically modify video flows and/or network resources in order to achieve a QoE fairness between users [50]. Thus, SDN techniques will play a crucial role in the design of the Tactile Internet, which is a combination of multisystems and multitechnologies that need to share the frequency spectrum as well as the physical infrastructure. In addition, existing multimedia distribution technologies have successful experiences in supporting adaptive multimedia streaming, which offers smooth real-time audiovisual services and solves the issues of network restrictions, energy consumption, and user-perceived quality [123, 193, 221]. Considerable effort has been made in this research direction and a large plethora of adaptive multimedia delivery solutions have been proposed in the literature. We argue that these solutions could teach us important lessons that can be further used in mulsemedia delivery: mulsemedia services can also be tailored to users based on the different network conditions and multisensorial devices.

To this end, one promising endeavor is that afforded by the Tactile Internet in 5G, which envisages an ultra-responsive and ultra-reliable network connectivity that enables the delivery of physical haptic experiences remotely and allows the building of real-time interactive systems [52]. Using predictive analysis together with artificial intelligence and changing the air interface and architecture design at the wireless edge, the Tactile Internet thus has the challenge to achieve $1 \mathrm{~ms}$ round-trip latency and to provide an enhanced haptic perception. If the Tactile Internet delivers on its potential, then we surmise that mulsemedia applications of the future can harness its abilities to deliver seamless synchronization between the different media components.

\subsection{Rendering: From Prototypes to Off-the-Shelf Devices}

After mulsemedia content has been transmitted over a network, different types of sensorial devices have to retrieve and translate the content to represent the appropriate effects [35]. An extensive review of olfactory displays following different classifications (location, how the scent is delivered) is presented in [130]. The authors analyze different setups and discuss the limitations of different technologies (both experimental and commercial) used in building olfactory displays. Haptic devices and their possible effects and applications are presented in [34]. A more recent effort in this direction is presented in [124], where the authors present the concept of altered touch through an integrated fingertip haptic display that uses integrated force, tactile and thermal feedback, and the appropriate effects [35]. An extensive review of olfactory displays following different classifications (location, how the scent is delivered) is presented in [130]. The authors analyze different setups and discuss limitations of different technologies (both experimental and commercial) used in building olfactory displays. Haptic devices and their possible effects and applications are presented in [34]. A more recent effort in this direction is presented in [124], where the authors present the concept of "altered touch" through an integrated fingertip haptic display that uses integrated force and tactile and thermal feedback and can be used with augmented reality applications.

One of the aims of this article is to offer guidance in the aspects that should be considered by researchers who explore the potential or the particularities of multisensory interaction. Thus, in Table 6, we focus on a list of prototype rendering devices presented in research papers by describing the context in which they were used, the feedback they provide, the research directions we identified as interesting to explore, and potential off-the-shelf commercial devices that anyone can use in replicating or extending the initial studies.

In this section, we have focused on different particularities related to production, distribution, and rendering of multisensory systems. Most of the existent studies in mulsemedia delivery or in 
Table 6. Rendering Devices

\begin{tabular}{|c|c|c|c|c|}
\hline & Prototype & Theme & $\begin{array}{l}\text { Interesting } \\
\text { Unexplored } \\
\text { Directions }\end{array}$ & Off-the-Shelf Devices \\
\hline \multirow{2}{*}{ 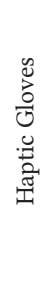 } & $\begin{array}{l}\text { Exoskeleton glove } \\
\text { with pin arrays [111] }\end{array}$ & $\begin{array}{l}\text { Force and tactile } \\
\text { feedback that allows } \\
\text { people to touch, } \\
\text { stretch, and pull virtual } \\
\text { fabrics }\end{array}$ & $\begin{array}{l}\text { Distinction } \\
\text { between } \\
\text { different fabrics }\end{array}$ & $\begin{array}{l}\text { Dexmo - exoskeleton glove that captures } \\
11 \text { DOF of users' hand motion and } \\
\text { provides force feedback of variable } \\
\text { stiffness [65] }\end{array}$ \\
\hline & Mood glove [117] & $\begin{array}{l}\text { Enrich moods in } \\
\text { films/music through } \\
\text { tactile sensations (eight } \\
\text { vibration patterns) }\end{array}$ & $\begin{array}{l}\text { Emotional } \\
\text { experience } \\
\text { through } \\
\text { cross-modality }\end{array}$ & $\begin{array}{l}\text { Gloveone/Avatar VR - tracks finger and } \\
\text { arm motions and produces haptic } \\
\text { sensations through vibrations }\end{array}$ \\
\hline \multirow[t]{2}{*}{ 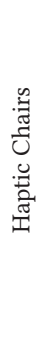 } & $\begin{array}{l}\text { Feel effects - Haptic } \\
\text { chair ( } 24 \text { tactors on } \\
\text { the back of the } \\
\text { chair). Effect } \\
\text { libraries: stroke, } \\
\text { pulse, motor, rain, } \\
\text { strike, travel [87]. }\end{array}$ & $\begin{array}{l}\text { Storytelling, story } \\
\text { listening }\end{array}$ & \multirow[t]{2}{*}{$\begin{array}{l}\text { Training for } \\
\text { disabled } \\
\text { (wheelchair } \\
\text { users) }\end{array}$} & \multirow{2}{*}{$\begin{array}{l}\text { Roto VR - Haptic chair with rumble } \\
\text { shakers fixed to the underside and back } \\
\text { of the chair (effect libraries: crashes, } \\
\text { flaps, turbulence - plane, race car, roller } \\
\text { coaster), VR amplifier (filters audio } \\
\text { signals and creates tactile feedback), } \\
\text { base and foot pedals (walk in VR). }\end{array}$} \\
\hline & $\begin{array}{l}\text { Haptic chair [139], } \\
\text { Emoti-chair [13] }\end{array}$ & $\begin{array}{l}\text { Enrich the music } \\
\text { experience for the deaf } \\
\text { by the touchable } \\
\text { vibrations }\end{array}$ & & \\
\hline \multirow{2}{*}{ 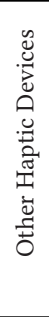 } & HALUX [204] & $\begin{array}{l}\text { Interactive skin for } \\
\text { digital sports based on } \\
\text { projections }\end{array}$ & $\begin{array}{l}\text { Investigate the } \\
\text { level of } \\
\text { immersion }\end{array}$ & $\begin{array}{l}\text { Rez Infinite - whole-body vibrotactile } \\
\text { interaction }\end{array}$ \\
\hline & $\begin{array}{l}\text { Jorro Beat [82] - } \\
\text { showerhead that } \\
\text { controls the water } \\
\text { flow and provides a } \\
\text { tactile stimulation } \\
\text { synchronized with } \\
\text { music }\end{array}$ & $\begin{array}{l}\text { Enrich the music } \\
\text { experience in the } \\
\text { bathroom }\end{array}$ & $\begin{array}{l}\text { Playing live } \\
\text { music with an } \\
\text { input interface }\end{array}$ & $\mathrm{n} / \mathrm{a}$ \\
\hline \multirow{2}{*}{ 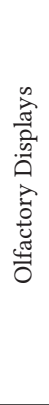 } & Wearable & $\begin{array}{l}\text { Product evaluation in } \\
\text { visual-olfactory } \\
\text { environment [18]; } \\
\text { low-cost wearable } \\
\text { display [75]; } \\
\text { miniaturized olfactory } \\
\text { display [71] }\end{array}$ & \multirow{2}{*}{$\begin{array}{l}\text { Generate } \\
\text { multiple odors } \\
\text { simultaneously; } \\
\text { create scents in } \\
\text { the vapor state }\end{array}$} & \multirow[t]{2}{*}{$\begin{array}{l}\text { Aroma foin - messenger app, } \\
\text { notification, odor card, DaleAir, Exhalia } \\
\text { AromaStick - personal mood changer for } \\
\text { office workers }\end{array}$} \\
\hline & Desktop & $\begin{array}{l}\text { Odor emanated by a } \\
\text { specific region of the } \\
\text { screen in an immersive } \\
\text { environment [114]; } \\
\text { cooking game with } \\
\text { odors [134] }\end{array}$ & & \\
\hline \multirow{3}{*}{ 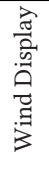 } & WindCube [122] & \multirow{3}{*}{$\begin{array}{l}\text { Create stable flow } \\
\text { patterns for directional } \\
\text { wind display; wind } \\
\text { direction perception } \\
{[136]}\end{array}$} & \multirow{3}{*}{$\begin{array}{l}\text { Cross-modal } \\
\text { effects with } \\
\text { other sensory } \\
\text { modalities; } \\
\text { precision of } \\
\text { wind perception }\end{array}$} & \multirow{3}{*}{$\begin{array}{l}\text { DC fans; Feelreal mask - two powerful } \\
\text { microcoolers (cool and hot air) }\end{array}$} \\
\hline & MSF [113] & & & \\
\hline & $\begin{array}{l}\text { Treadpod Active } \\
\text { Wind Tunnel } \\
\text { TPAWT [99], [98] }\end{array}$ & & & \\
\hline
\end{tabular}

creating new ways of interaction with technology consider bisensory settings. However, as presented in previous subsections, the created multisensorial systems started to be populated with tri- or multiple sensory options from creation to rendering. All these tools and devices allow researchers to further address the set of challenges presented in the next section. 


\section{FUTURE DIRECTIONS}

Media production and consumption play an important role in our everyday lives. Research on interactive experiences with mulsemedia is a growing field of study subdivided into topics related to cross-modal processes, content production, system design and architecture, application and evaluation of users' experience, and development of new interaction paradigms. While in the 20th century the interest in the media industry was on the visual, the present demands an investigation of touch, taste, and smell as sensory interaction modalities. Starting from this, a set of questions arise: which mulsemedia experience to design for, how can this be achieved, and how to evaluate the QoE. Recent advances in experimental psychology (described partially in Section 2) and HCI [147] are two important sources of inspiration [145].

Previous work showed that researchers focused on rendering and production of haptic, sound, olfaction, or taste from the point of view that they represent a single medium engaging a single sense [61], [130], [35]. In this article, and indeed, in our work, we are interested in the multi-multi perspective where multiple types of media engage multiple senses.

\subsection{Research Topics}

Rendering continues to present challenges in creating a holistic multisensory percept in a digital context. An important characteristic of the rendering devices should be adaptability that can happen automatically or through the help of the designer or end-user. In order to ensure correct rendering, devices that are operable by nonexperts need easy methods for troubleshooting. In Table 6, we present interesting research prototypes and their corresponding off-the-shelf devices that could be considered isolated or combined in building mulsemedia setups.

Design guidelines need to be further developed. As in the case of the standardization of HTML/CSS, and Blu-Ray versus HD DVD, diverse file formats and infrastructures will emerge. Given the diversity of multisensory technologies and experiences, we expect these to be centered around paradigms that can propose ways to work with mulsemedia content and which can be applied to multiple devices in a class. Best practices in working with multisensory content have yet to be formulated. An interesting study about the haptic design process was presented in [172], where the authors identify current obstacles in the design of haptic user experiences and present the results of intensive interviews with six professional haptic designers. The authors make valuable recommendations for accelerating the development of HaXD that can be applied also in a mulsemedia context. Another paper that provides a tutorial and recommendations on the key steps to conduct olfactory-based evaluation of the QoE is presented in [127]. This represents an important step in proposing a standardized methodology to conduct subjective mulsemedia quality assessment. However, there is still a need for more guidelines since they will enable the support of mulsemedia researchers and HCI designers alike. It is important to develop a set of best practices to guide people in the design of meaningful mulsemedia experiences.

Non-Aristotelian senses are not yet intensively targeted by digital mulsemedia systems, where the focus is overwhelmingly, if not exclusively, on the traditional five Aristotelian senses. While interoceptive senses like proprioception have been studied in the nondigital world, their stimulation and integration through traditional and/or nontraditional media types has yet to be explored in the digital world. However, while steps in this direction have been made in different virtual environments for the treatment of phobias or for the investigation of the contribution of proprioception, this has been done by calling upon intermediate modalities, such as force feedback, which stimulate the interoceptive senses. However, such incipient work did not make any formal conclusions since follow-up research is necessary to validate their findings. 
Taste was identified in several research papers as one of the least investigated senses in terms of sensory interaction modalities [61], [148]. So far, things have not changed substantially. Although gustation has been extensively studied to understand the functionality of the taste system, there is still a lack of understanding related to how taste can be exploited in developing new ways of interaction with technology. An interesting work in this context is presented in [146]. After a thorough analysis that is centered on user experience, the authors of this work identified three main types of characteristics that define taste experiences: temporality, affective reactions, and embodiment. These characteristics are presented as a framework for designing gustatory experiences. As such, one of the main contributions of the work in discussion is that it provides a rich understanding and a vocabulary of the gustatory experience and its influence on user experience as well as new tools to design such experiences. Both electrical and thermal stimulation of taste require more focused experimental studies considering aspects such as material characteristics (i.e., gold vs. silver), position on the tongue, and the waveform of the electrical signal. Moreover, it is very important to experiment with different physiological and psychological aspects of the sensation of taste at the intersection with other sensory cues. As highlighted in [206], there is a growing interest in enhancing HCI and food interaction design by understanding the multisensory influences on flavor perception. Scenarios where visual, auditory, and haptic cues were used for modulating flavor are presented, while the authors also summarize important challenges related to the need for long-term follow-up investigations that could add value to flavor augmentation.

Cross-modal correspondences and multisensory substitution. Cross-modal correspondences still present a number of unanswered questions related to sensory cue integration and to how correspondences affect metaphorical understanding, feelings of "knowing," behavior, learning, and perceptual experiences [39]. Practical guidelines for the design of experiments that might shed new light on cross-modal correspondences are presented in [153]. Continuously investigating this direction could also benefit the development of more effective sensory substitution devices, since it has been shown that cross-modal correspondences enhance the performance of color to sound systems [67].

Attention modeling. There are often situations when an interface designer wants to capture the attention of the user. Attention is a cognitive concept that determines how particular sensory input, perceptual objects, thoughts, or courses of action are selected for further processing. Typically, researchers tended to focus on an individual sensory modality, ignoring the other senses [187], and noticed that each sense presents different capabilities: vision is precise for spatial information, sound is effective in the perception of temporal information, and haptics can be used in processing both temporal and spatial [180]. However, it has been shown that multisensory audio/tactile cueing improves the performance (speed and accuracy) of visual search and reduces the amount of mental workload [68]. Thus, cross-modal cueing represents a feasible approach for enhancing task performance without causing an increase in the attention attributed to a singular sensory modality [81]. The magnitude of cueing effects was measured in a laboratory environment for HCI or for driving. A multisensory driver described in [78] provides interesting interface design guidelines supported by multisensory human perception research and has the potential to help the development of ergonomic interfaces. In designing a car interface, implications for VT warning signals of the cross-modal links between touch and vision in motion processing have also been presented in [76]. However, the same authors show that laboratory-based studies on spatial attention do not capture all the key factors of real-world situations and present a set of recommendations that could help researchers without compromising the value of their experiments [77].

Building databases, libraries of effects, examples, and rapid prototyping tools. The use of multisensory media is nontrivial, and thus it needs to be supported through a variety of tools that 
help the design process. Most of the existing libraries (media interactions [173], [33], TouchSense: for accessible wayfinding [218]) do not offer examples, or indeed the possibility to decompose these effects. The latest features allow parameters to be adjusted [87] and provide faceted library search and browsing [177], but most times designers need to choose predefined effects or to build them from scratch. An interesting approach for VT effects is the Macaron tool [175] that includes a web-based editor and a gallery for interactive design [102]. The authors' observations present implications for other editing tools.

\subsection{Application Areas}

Mulsemedia and performing arts. Interactive art started to be increasingly present not only in art galleries but also in events like ISEA and Prix Ars Electronica or in demo tracks at academic conferences like CHI or SIGGRAPH. Multisensory interactive art installations perform an openend exploration, questioning the role of multisensory interfaces for communication. Art offers an alternative approach and allows researchers to gain insights into the interactive process, facilitating the collaboration between artists and technologists. In [137], the authors identify a theoretical framework of interactive installations and highlight their relevance to $\mathrm{HCI}$ through relevant examples. Art installations could lead to a better understanding of underexploited senses like taste and smell. In [103] the authors propose an installation exhibited at SIGGRAPH ASIA Art Gallery that allows the user to draw the lollipop on a virtual screen and print it with fragrance inks. Tate Sensorium $^{10}$ was a winning project of the IK Prize 2015 Award. It featured an immersive display with four paintings from the Tate Collection that allowed viewers to experience sounds, smells, tastes, and physical forms inspired by these artworks while having their psychological responses recorded.

An ongoing project funded by the European Commission's Horizon 2020 Framework, Accessible Resources for Cultural Heritage EcoSystems (ARCHES), ${ }^{11}$ aims to exploit multisensorial devices and media among other technologies in order to create more inclusive environments at museums and cultural heritage sites for people having difficulties associated with perception, memory, cognition, and communication. We argue that mulsemedia systems can have a high impact on helping people with different disabilities not only in art but also in other aspects of human life, such as education. Therefore, we consider this to be a challenging but worthwhile research direction to explore in the context of mulsemedia systems.

We are at the point where technology offers affordable tools that allow us to create new experiences and gather knowledge. It is important to understand how these tools should be used, and in this process, keeping this experimental mindset often met in creating art would be key to give insights and clarify aspects that can be used also in other fields.

Wearable mulsemedia. The evolution of multisensory technology embedded into wearables represents a new modality for people to experience life enhancing all the human senses. Haptics cannot be dismissed anymore as boring vibrations that alert you to messages. Now, prototype touchscreens can use ultrasonics to create the "feel" of different objects while haptic motors are becoming smaller and more flexible. People can send hugs over distance with the "Hug Shirt," 12 feel vibrational cues that help them keep up the rhythm with "Soundbrenner," 13 or experience what a player feels during games through Alert Shirt. ${ }^{14}$ With the upcoming release of "watchOS 3," Apple

\footnotetext{
${ }^{10}$ Sensorium: http://www.tate.org.uk/whats-on/tate-britain/display/ik-prize-2015-tate-sensorium.

${ }^{11}$ ARCHES: http://arches-project.eu/.

${ }^{12}$ The Hug Shirt: http://cutecircuit.com/the-hug-shirt/.

${ }^{13}$ Sounbrenner: http://www.soundbrenner.com/.

${ }^{14}$ Alert Shirt: http://wearableexperiments.com/alert-shirt/.
} 
is pushing things further. Breathe ${ }^{15}$ its new application designed to coach people through stressrelieving breathing patterns, uses the Taptic engine to deliver subtle physical prompts on when to inhale and exhale. Moreover, these advancements in affordable wearable technology have the potential to also help people with special needs. Lechal ${ }^{16}$ is a haptic footwear that helps the visually impaired navigate. Unlike smartphones and tablets, which rely on people looking at them, the lack of display space and digital interfaces makes multisensory feedback an even more powerful tool. Olfactory displays are still in a prototype status [71, 118], but it would be interesting to see how the market evolves in this direction. Interesting horizons can be envisaged through devices like Aromastic, a mobile scent dispenser that aims to act as a personal mood changer for busy professionals. These types of initiatives seem promising also in respect to multisensory therapy (e.g., Snoezelen), which has been successfully applied to alleviate the symptoms associated with a wide range of pathologies [22].

Mulsemedia and e-learning. With the rapid growth and development of information and communication technologies, e-learning has seen a fast evolution over the past decade. Mobile and multimedia technologies have also changed radically the online learning landscape $[59,60]$. The advances in wearables and mobile technologies such as improved network speeds, improved processing power, improved graphics, and higher-resolution displays enable enhanced, more complex mobile learning experiences. Olfaction and haptic interfaces have started to be evaluated in the context of education $[108,164]$, predominantly in science and mathematics but also in social sciences [121]. However, since the majority of educational virtual environments are focused on visual representation [157], there is still a need to investigate the capabilities of a multisensory system and its effects on learning outcomes and knowledge retention. In [179], the authors discussed the benefits of multisensory learning over a unisensory paradigm. However, the authors emphasize the fact that the magnitude of this benefit is dependent on the congruency of the stimuli; e.g., the learning environment must closely map what users have experienced in nature, supporting the findings in [72]. Cross-modal correspondences and cross-modal substitutions can also play an important role in the learning process (also for people with disabilities) that has to be analyzed. Over the last few years, the European Union Framework programs and Horizon 2020 have supported a number of projects in the multimodal space. NEWTON ${ }^{17}$ (Networked labs for training sciences and technologies) is of relevance for the present study since it focuses on multisensorial aspects in learning STEM subjects [27].

Mulsemedia in e-commerce and advertising. With the current upsurge in technology and wearables on one hand and the increasing preference of customers toward online shopping on the other hand, mulsemedia has the potential to influence and change consumer behavior. Several studies have shown an increase of satisfaction and a better emotional state when using environmental cues. Ambient cues (colors and scents) have an impact on users' behavior, with cool visual and olfactory cues (blue or citrus-mint) rated higher than warm cues. Also, the influence of touch on online shopping attitudes was demonstrated in [105] for a Korean population. Using devices like the smelling screen [114] or the FeelReal Helmet, digital marketers can improve the store environment with both design and ambient factors [91] by proposing a new interface that can be applied to a variety of visual contents such as ads and websites.

Sensory marketing engages customers' senses and can influence advertisement design and effectiveness because of its influence on perception, judgment, and behavior. An extensive review discusses the role of sensory marketing in driving advertisement effectiveness, showing that

\footnotetext{
${ }^{15}$ Breathe: https://support.apple.com/en-gb/HT206999.

${ }^{16}$ Lechal: http://www.lechal.com/.

${ }^{17}$ EU H2020 NEWTON: http://www.newtonproject.eu.
} 
product evaluation is enhanced by touch and smell, attention and persuasiveness are affected by music, memory is enhanced by smell, and taste perception is improved under multisensory stimulation [96]. Well-implemented sensory experiences have positive effects on brand equity, with studies showing that participants agreed that sensory stimulators are congruent with brand identity [11].

\section{CONCLUSION}

While multisensory interaction and displays have been studied in quite some depth in the nondigital world (e.g., in psychology, education, therapy, performing arts, etc.), they are relative newcomers to the digital world. Moreover, while multimodal systems have a long track record of being studied in the digital world, digital mulsemedia systems are again relative newcomers on the research scene, and, in the current article, we have reviewed research efforts targeting this extra dimension of the multimedia experience.

It is already obvious that mulsemedia systems have the potential to make more efficient use of the human perceptual and cognitive capabilities because the human brain has evolved in a multisensory environment. In the current review, we tried to offer a full picture of the spectrum of multisensory systems starting with the neurological processes involved (from cross-modal correspondences to multisensory integration), continuing with the workflow for production-distributionrendering, and ending with challenges that still need to be addressed. We made sure to emphasize important aspects related to multistream synchronization, adaptation, fast prototyping, and offthe-shelf devices, and we identified areas that could have a major benefit from this multisensorial approach. All are worthy of future endeavors.

Mulsemedia systems are multi-multi systems, where multiple (more than three) senses are engaged by multiple media. In contrast to multimodal systems, mulsemedia systems are all about the media and not the modality; the focus here is on the diverse new, nontraditional media types; their production, distribution, and rendering; and the issues raised when integrating nontraditional and traditional digital media in mulsemedia systems. As our artile has shown, progress is being made in our understanding of mulsemedia systems, yet there are challenges and opportunities galore to be explored and overcome in the quest to transcend the overwhelmingly bisensorial nature of digital multimedia into the multisensorial one of mulsemedia.

\section{REFERENCES}

[1] J. W. Adams, L. Paxton, K. Dawes, K. Burlak, M. Quayle, and P. G. McMenamin. 2015. 3D printed reproductions of orbital dissections: A novel mode of visualising anatomy for trainees in ophthalmology or optometry. British fournal of Ophthalmology 99, 9 (2015), 1162-1167. DOI : http://dx.doi.org/10.1136/bjophthalmol-2014306189 arXiv:http://bjo.bmj.com/content/99/9/1162.full.pdf.

[2] O. A. Ademoye and G. Ghinea. 2009. Synchronization of olfaction-enhanced multimedia. IEEE Transactions on Multimedia 11, 3 (April 2009), 561-565. DOI : http://dx.doi.org/10.1109/TMM.2009.2012927

[3] O. A. Ademoye and G. Ghinea. 2013. Information recall task impact in olfaction-enhanced multimedia. ACM Transactions on Multimedia Computing, Communications, and Applications (TOMM) 9, 3 (2013), 17.

[4] O. A. Ademoye, N. Murray, G.-M. Muntean, and G. Ghinea. 2016. Audio masking effect on inter-component skews in olfaction-enhanced multimedia presentations. ACM Transactions on Multimedia Computing, Communications, and Applications (TOMM) 12, 4, Article 51 (Aug. 2016), 14 pages. DOI : http://dx.doi.org/10.1145/2957753

[5] A. Aijaz, M. Dohler, A. H. Aghvami, V. Friderikos, and M. Frodigh. 2017. Realizing the tactile internet: Haptic communications over next generation 5G cellular networks. IEEE Wireless Communications 24, 99 (October 2017), 82-89. DOI : http://dx.doi.org/10.1109/MWC.2016.1500157RP

[6] D. Alais and J. Cass. 2010. Multisensory perceptual learning of temporal order: Audiovisual learning transfers to vision but not audition. PloS One 5, 6 (2010), e11283.

[7] F. Arafsha, L. Zhang, H. Dong, and A. E. Saddik. 2015. Contactless haptic feedback: State of the art. In 2015 IEEE International Symposium on Haptic, Audio and Visual Environments and Games (HAVE'15). 1-6. DOI : http://dx.doi. org/10.1109/HAVE.2015.7359447 
[8] A. Baddeley. 1992. Working memory. Science 255, 5044 (1992), 556-559.

[9] P. J. Barnard and J. D. Teasdale. 1991. Interacting cognitive subsystems: A systemic approach to cognitive-affective interaction and change. Cognition and Emotion 5, 1 (1991), 1-39. DOI : http://dx.doi.org/10.1080/02699939108411021

[10] K. Belkin, R. Martin, S. E. Kemp, and A. N. Gilbert. 1997. Auditory pitch as a perceptual analogue to odor quality. Psychological Science 8, 4 (1997), 340-342.

[11] B. Alexander and K. Nobbs. 2016. Multi-sensory fashion retail experiences: The impact of sound, smell, sight and touch on consumer based brand equity. In Handbook of Research on Global Fashion Management and Merchandising, Alessandra Vecchi and Chitra Buckley (Eds.). IGI Global, Hershey, PA, 420-443. Retrieved from http:// services.igi-global.com/resolvedoi/resolve.aspx?doi=10.4018/978-1-5225-0110-7.ch017.

[12] N. Bolognini, F. Frassinetti, A. Serino, and E. Làdavas. 2005. "Acoustical visio" of below threshold stimuli: Interaction among spatially converging audiovisual inputs. Experimental Brain Research 160, 3 (2005), 273-282.

[13] C. Branje, M. Karam, D. Fels, and F. Russo. 2009. Enhancing entertainment through a multimodal chair interface. In 2009 IEEE Toronto International Conference Science and Technology for Humanity (TIC-STH'09). 636-641. DOI : http:// dx.doi.org/10.1109/TIC-STH.2009.5444421

[14] K. Bronner, K. Frieler, H. Bruhn, R. Hirt, and D. Piper. 2012. What is the sound of citrus? Research on the correspondences between the perception of sound and flavour. In Proceedings of the 12th International Conference of Music Perception and Cognition (ICMPC) and the 8th Triennial Conference of the European Society for the Cognitive Sciences of Music (ESCOM). 142-148.

[15] M. Bruijnes, G. Huisman, and D. Heylen. 2016. Tasty tech: Human-food interaction and multimodal interfaces. In Proceedings of the 1st Workshop on Multi-Sensorial Approaches to Human-Food Interaction. ACM, 4.

[16] L. Cancar, A. Díaz, A. Barrientos, D. Travieso, and D. M. Jacobs. 2013. Tactile-sight: A sensory substitution device based on distance-related vibrotactile flow. International fournal of Advanced Robotic Systems 10, 6 (2013), 272.

[17] S. K. Card. 1981. The model human processor: A model for making engineering calculations of human performance. Proceedings of the Human Factors Society Annual Meeting 25, 1 (1981), 301-305. DOI : http://dx.doi.org/10. 1177/107118138102500180

[18] M. Carulli, M. Bordegoni, and U. Cugini. 2015. Visual-olfactory immersive environment for product evaluation. In 2015 IEEE Virtual Reality (VR'15). 161-162. DOI : http://dx.doi.org/10.1109/VR.2015.7223345

[19] U. Castiello, G. M. Zucco, V. Parma, C. Ansuini, and R. Tirindelli. 2006. Cross-modal interactions between olfaction and vision when grasping. Chemical Senses 31, 7 (2006), 665-671.

[20] J. Cha, Y. Seo, Y. Kim, and J. Ryu. 2007. An authoring/editing framework for haptic broadcasting: Passive haptic interactions using MPEG-4 BIFS. In 2nd foint EuroHaptics Conference and Symposium on Haptic Interfaces for Virtual Environment and Teleoperator Systems (WHC'07). 274-279. DOI : http://dx.doi.org/10.1109/WHC.2007.20

[21] A. Chalmers, D. Howard, and C. Moir. 2009. Real virtuality: A step change from virtual reality. In Proceedings of the 25th Spring Conference on Computer Graphics (SCCG'09). ACM, New York, NY, 9-16. DOI : http://dx.doi.org/10.1145/ 1980462.1980466

[22] S. W-c. Chan, D. R. Thompson, J. P. C. Chau, W. W. S. Tam, I. W. S. Chiu, and S. H. S. Lo. 2010. The effects of multisensory therapy on behaviour of adult clients with developmental disabilities: A systematic review. International Journal of Nursing Studies 47, 1 (2010), 108-122.

[23] T. Chatzidimitris, D. Gavalas, and D. Michael. 2016. SoundPacman: Audio augmented reality in location-based games. In 2016 18th Mediterranean Electrotechnical Conference (MELECON'16). 1-6. DOI : http://dx.doi.org/10.1109/MELCON. 2016.7495414

[24] B. Choi, E. S. Lee, and K. Yoon. 2011. Streaming media with sensory effect. In 2011 International Conference on Information Science and Applications. 1-6. DOI : http://dx.doi.org/10.1109/ICISA.2011.5772390

[25] D. L. Clements, S. Sato, and A. Portela Fonseca. 2016. Cosmic sculpture: A new way to visualise the cosmic microwave background. European fournal of Physics 38, 1 (2016), 015601.

[26] E. Cooke and E. Myin. 2011. Is trilled smell possible? How the structure of olfaction determines the phenomenology of smell. Journal of Consciousness Studies 18, 11-12 (2011), 59-95.

[27] A. Covaci, G. Ghinea, C.-H. Lin, S.-H. Huang, and J.-L. Shih. 2018. Multisensory games-based learning-lessons learnt from olfactory enhancement of a digital board game. Multimedia Tools and Applications 77, 16 (2018), 21245-21263.

[28] A.-S. Crisinel and C. Spence. 2010. As bitter as a trombone: Synesthetic correspondences in nonsynesthetes between tastes/flavors and musical notes. Attention, Perception, \& Psychophysics 72, 7 (2010), 1994-2002.

[29] A.-S. Crisinel and C. Spence. 2009. Implicit association between basic tastes and pitch. Neuroscience Letters 464, 1 (2009), 39-42.

[30] A.-S. Crisinel and C. Spence. 2010. A sweet sound? Food names reveal implicit associations between taste and pitch. Perception 39, 3 (2010), 417-425

[31] A.-S. Crisinel and C. Spence. 2012. A fruity note: Crossmodal associations between odors and musical notes. Chemical Senses 37, 2 (2012), 151-158. DOI : http://dx.doi.org/10.1093/chemse/bjr085

[32] A. Cruz and B. G. Green. 2000. Thermal stimulation of taste. Nature 403, 6772 (2000), 889.

ACM Computing Surveys, Vol. 51, No. 5, Article 91. Publication date: September 2018. 
[33] H. Culbertson, J. Unwin, and K. J. Kuchenbecker. 2014. Modeling and rendering realistic textures from unconstrained tool-surface interactions. IEEE Transactions on Haptics 7, 3 (July 2014), 381-393. DOI : http://dx.doi.org/10.1109/TOH. 2014.2316797

[34] F. Danieau, J. Bernon, J. Fleureau, P. Guillotel, N. Mollet, M. Christie, and A. Lécuyer. 2013. H-Studio: An authoring tool for adding haptic and motion effects to audiovisual content. In Proceedings of the Adjunct Publication of the 26th Annual ACM Symposium on User Interface Software and Technology (UIST'13 Adjunct). ACM, New York, NY, 83-84. DOI : http://dx.doi.org/10.1145/2508468.2514721

[35] F. Danieau, A. Lecuyer, P. Guillotel, J. Fleureau, N. Mollet, and M. Christie. 2013. Enhancing audiovisual experience with haptic feedback: A survey on HAV. IEEE Transactions on Haptics 6, 2 (April 2013), 193-205. DOI : http://dx.doi. org/10.1109/TOH.2012.70

[36] J. Delwiche. 1996. Are there "basic" tastes?Trends in Food Science \& Technology 7, 12 (1996), 411-415. DOI : http:// dx.doi.org/10.1016/S0924-2244(96)20010-X

[37] M. L. Dematte, D. Sanabria, R. Sugarman, and C. Spence. 2006. Cross-modal interactions between olfaction and touch. Chemical Senses 31, 4 (2006), 291-300.

[38] O. Deroy, I. Fasiello, V. Hayward, and M. Auvray. 2016. Differentiated audio-tactile correspondences in sighted and blind individuals. Fournal of Experimental Psychology: Human Perception and Performance 42, 8 (2016), 1204.

[39] O. Deroy and C. Spence. 2016. Crossmodal correspondences: Four challenges. Multisensory Research 29, 1-3 (2016), $29-48$.

[40] O. Deroy and D. Valentin. 2011. Tasting liquid shapes: Investigating the sensory basis of cross-modal correspondences. Chemosensory Perception 4, 3 (2011), 80.

[41] H. Q. Dinh, N. Walker, L. F. Hodges, C. Song, and A. Kobayashi. 1999. Evaluating the importance of multi-sensory input on memory and the sense of presence in virtual environments. In Proceedings IEEE Virtual Reality (Cat. No. 99CB36316). 222-228. DOI : http://dx.doi.org/10.1109/VR.1999.756955

[42] N. F. Dixon and L. Spitz. 1980. The detection of auditory visual desynchrony. Perception 9, 6 (1980), 719-721. DOI: http://dx.doi.org/10.1068/p090719 arXiv:http://dx.doi.org/10.1068/p090719 PMID: 7220244.

[43] D. Dmitrenko, E. Maggioni, C. T. Vi, and M. Obrist. 2017. What did I sniff? Mapping scents onto driving-related messages. In Proceedings of the 9th International Conference on Automotive User Interfaces and Interactive Vehicular Applications (AutomotiveUI'17). ACM, 154-163.

[44] H. Dong, Y. Gao, H. A. Osman, and A. E. Saddik. 2015. Development of a web-based haptic authoring tool for multimedia applications. In 2015 IEEE International Symposium on Multimedia (ISM'15). 13-20. DOI: http://dx.doi. org/10.1109/ISM.2015.71

[45] A. E. Dubin and A. Patapoutian. 2010. Nociceptors: The sensors of the pain pathway. fournal of Clinical Investigation 120, 11 (2010), 3760-3772.

[46] B. Durie. 2017. Senses Special: Doors of Perception. Retrieved from https://www.newscientist.com/article/ mg18524841-600-senses-special-doors-of-perception/. Accessed: March 19, 2017.

[47] M. Eldridge, E. Saltzman, and A. Lahav. 2010. Seeing what you hear: Visual feedback improves pitch recognition. European Fournal of Cognitive Psychology 22, 7 (2010), 1078-1091. DOI : http://dx.doi.org/10.1080/09541440903316136 arXiv:http://dx.doi.org/10.1080/09541440903316136

[48] M. J. Enriquez and K. E. MacLean. 2003. The Hapticon editor: A tool in support of haptic communication research. In Proceedings of the 11th Symposium on Haptic Interfaces for Virtual Environment and Teleoperator Systems, 2003 (HAPTICS'03). 356-362. DOI : http://dx.doi.org/10.1109/HAPTIC.2003.1191310

[49] L. Escobedo, M. Tentori, E. Quintana, J. Favela, and D. Garcia-Rosas. 2014. Using augmented reality to help children with autism stay focused. IEEE Pervasive Computing 13, 1 (2014), 38-46.

[50] C. F. Lai, R. H. Hwang, H. C. Chao, M. M. Hassan, and A. Alamri. 2015. A buffer-aware HTTP live streaming approach for SDN-enabled 5G wireless networks. IEEE Network 29, 1 (Jan. 2015), 49-55. DOI : http://dx.doi.org/10.1109/MNET. 2015.7018203

[51] M. Falasconi, I. Concina, E. Gobbi, V. Sberveglieri, A. Pulvirenti, and G. Sberveglieri. 2012. Electronic nose for microbiological quality control of food products. International fournal of Electrochemistry 2012 (2012).

[52] G. P. Fettweis. 2014. The tactile internet: Applications and challenges. IEEE Vehicular Technology Magazine 9, 1 (March 2014), 64-70. DOI : http://dx.doi.org/10.1109/MVT.2013.2295069

[53] C. Forsythe, H. Liao, M. C. S. Trumbo, and R. E. Cardona-Rivera. 2014. Cognitive Neuroscience of Human Systems: Work and Everyday Life. CRC Press.

[54] S. Gane, D. Georganakis, K. Maniati, M. Vamvakias, N. Ragoussis, E. M. C. Skoulakis, and L. Turin. 2013. Molecular vibration-sensing component in human olfaction. PLOS ONE 8, 1 (2013), 1-7. DOI : http://dx.doi.org/10.1371/journal. pone. 0055780 
[55] G. Ghinea and O. Ademoye. 2012. User perception of media content association in olfaction-enhanced multimedia. ACM Transactions on Multimedia Computing, Communications, and Applications (TOMM) 8, 4, Article 52 (Nov. 2012), 19 pages. DOI : http://dx.doi.org/10.1145/2379790.2379794

[56] G. Ghinea and O. Ademoye. 2015. Olfactory media impact on task performance: The case of a word search game. In 2015 International Conference on Interactive Mobile Communication Technologies and Learning (IMCL'15). IEEE, 296-300.

[57] G. Ghinea and O. A. Ademoye. 2010. Perceived synchronization of olfactory multimedia. IEEE Transactions on Systems, Man, and Cybernetics - Part A: Systems and Humans 40, 4 (July 2010), 657-663. DOI : http://dx.doi.org/10.1109/ TSMCA.2010.2041224

[58] G. Ghinea and O. A. Ademoye. 2011. Olfaction-enhanced multimedia: Perspectives and challenges. Multimedia Tools and Applications 55, 3 (2011), 601-626.

[59] G. Ghinea and S. Y. Chen. 2006. Perceived quality of multimedia educational content: A cognitive style approach. Multimedia Systems 11, 3 (2006), 271-279.

[60] G. Ghinea and S. Y. Chen. 2008. Measuring quality of perception in distributed multimedia: Verbalizers vs. imagers. Computers in Human Behavior 24, 4 (2008), 1317-1329.

[61] G. Ghinea, C. Timmerer, W. Lin, and S. R. Gulliver. 2014. Mulsemedia: State of the art, perspectives, and challenges. ACM Transactions on Multimedia Computing, Communications, and Applications (TOMM) 11, 1s, Article 17 (Oct. 2014), 23 pages. DOI : http://dx.doi.org/10.1145/2617994

[62] G. Gingras, B. A. Rowland, and B. E. Stein. 2009. The differing impact of multisensory and unisensory integration on behavior. Fournal of Neuroscience 29, 15 (2009), 4897-4902.

[63] M. Grimshaw. 2014. The Oxford Handbook of Virtuality. Oxford University Press.

[64] K. Gsöllpointner, R. Schnell, and R. K. Schuler. 2016. Digital Synesthesia: A Model for the Aesthetics of Digital Art. Gruyter, Walter de GmbH.

[65] X. Gu, Y. Zhang, W. Sun, Y. Bian, D. Zhou, and P. O. Kristensson. 2016. Dexmo: An inexpensive and lightweight mechanical exoskeleton for motion capture and force feedback in VR. In Proceedings of the 2016 CHI Conference on Human Factors in Computing Systems (CHI'16). ACM, New York, 1991-1995. DOI : http://dx.doi.org/10.1145/2858036. 2858487

[66] R. Guetta and P. Loui. 2017. When music is salty: The crossmodal associations between sound and taste. PLOS ONE 12, 3 (03 2017), 1-14. DOI : http://dx.doi.org/10.1371/journal.pone.0173366

[67] G. Hamilton-Fletcher, T. D. Wright, and J. Ward. 2016. Cross-modal correspondences enhance performance on a colour-to-sound sensory substitution device. Multisensory Research 29, 4-5 (2016), 337-363.

[68] P. A. Hancock, J. E. Mercado, J. Merlo, and J. B. F. Van Erp. 2013. Improving target detection in visual search through the augmenting multi-sensory cues. Ergonomics 56, 5 (2013), 729-738.

[69] G. Hanson-Vaux, A.-S. Crisinel, and C. Spence. 2013. Smelling shapes: Crossmodal correspondences between odors and shapes. Chemical Senses 38, 2 (2013), 161-166.

[70] K. Hapeshi and D. Jones. 1992. Interactive multimedia for instruction: A cognitive analysis of the role of audition and vision. International fournal of Human-Computer Interaction 4, 1 (1992), 79-99.

[71] K. Hashimoto and T. Nakamoto. 2016. Tiny olfactory display using surface acoustic wave device and micropumps for wearable applications. IEEE Sensors fournal 16, 12 (2016), 4974-4980.

[72] M. Haverkamp. 2013. Synesthetic Design: Handbook for a Multi-sensory Approach. Walter de Gruyter.

[73] C. H. Hawkes. 2004. Olfaction taste and cognition. Brain 127, 1 (2004), 231-231.

[74] V. Hayward, O. R. Astley, M. Cruz-Hernandez, D. Grant, and G. Robles-De-La-Torre. 2004. Haptic interfaces and devices. Sensor Review 24, 1 (2004), 16-29. DOI : http://dx.doi.org/10.1108/02602280410515770

[75] N. S. Herrera and R. P. McMahan. 2014. Development of a simple and low-cost olfactory display for immersive media experiences. In Proceedings of the 2nd ACM International Workshop on Immersive Media Experiences (ImmersiveMe'14). ACM, New York, 1-6. DOI : http://dx.doi.org/10.1145/2660579.2660584

[76] C. Ho, R. Gray, and C. Spence. 2014. Reorienting driver attention with dynamic tactile cues. IEEE Transactions on Haptics 7, 1 (Jan. 2014), 86-94. DOI : http://dx.doi.org/10.1109/TOH.2013.62

[77] C. Ho, R. Gray, and C. Spence. 2014. To what extent do the findings of laboratory-based spatial attention research apply to the real-world setting of driving? IEEE Transactions on Human-Machine Systems 44, 4 (Aug. 2014), 524-530. DOI : http://dx.doi.org/10.1109/THMS.2014.2316502

[78] C. Ho and C. Spence. 2012. The Multisensory Driver: Implications for Ergonomic Car Interface Design. Ashgate Publishing.

[79] K. Hong, J. Lee, and S. Choi. 2013. Demonstration-based vibrotactile pattern authoring. In Proceedings of the 7th International Conference on Tangible, Embedded and Embodied Interaction (TEI'13). ACM, New York, 219-222. DOI : http://dx.doi.org/10.1145/2460625.2460660 
[80] K. Hong, J. Lee, and S. Choi. 2013. Demonstration-based vibrotactile pattern authoring. In Proceedings of the 7th International Conference on Tangible, Embedded and Embodied Interaction (TEI'13). ACM, New York, 219-222. DOI : http://dx.doi.org/10.1145/2460625.2460660

[81] K. Hopkins, S. J. Kass, L. D. Blalock, and J. C. Brill. 2017. Effectiveness of auditory and tactile crossmodal cues in a dual-task visual and auditory scenario. Ergonomics 60, 5 (2017), 692-700.

[82] K. Hoshino, M. Koge, T. Hachisu, R. Kodama, and H. Kajimoto. 2015. Jorro beat: Shower tactile stimulation device in the bathroom. In Proceedings of the 33rd Annual ACM Conference Extended Abstracts on Human Factors in Computing Systems (CHI EA'15). ACM, New York, 1675-1680. DOI : http://dx.doi.org/10.1145/2702613.2732841

[83] S. Hoshino, Y. Ishibashi, N. Fukushima, and S. Sugawara. 2011. QoE assessment in olfactory and haptic media transmission: Influence of inter-stream synchronization error. In 2011 IEEE International Workshop Technical Committee on Communications Quality and Reliability (CQR'11). IEEE, 1-6.

[84] L. Iordanescu, E. Guzman-Martinez, M. Grabowecky, and S. Suzuki. 2008. Characteristic sounds facilitate visual search. Psychonomic Bulletin \& Review 15, 3 (2008), 548-554.

[85] M. Ischer, N. Baron, C. Mermoud, I. Cayeux, C. Porcherot, D. Sander, and S. Delplanque. 2014. How incorporation of scents could enhance immersive virtual experiences. Applied Olfactory Cognition 119, 3 (2014), 4.

[86] A. Israr, S. Zhao, and O. Schneider. 2015. Exploring embedded haptics for social networking and interactions. In Proceedings of the 33rd Annual ACM Conference Extended Abstracts on Human Factors in Computing Systems (CHI EA'15). ACM, New York, 1899-1904. DOI : http://dx.doi.org/10.1145/2702613.2732814

[87] A. Israr, S. Zhao, K. Schwalje, R. Klatzky, and J. Lehman. 2014. Feel effects: Enriching storytelling with haptic feedback. ACM Transactions on Applied Perception 11, 3, Article 11 (Sept. 2014), 17 pages. DOI : http://dx.doi.org/10.1145/ 2641570

[88] D. Jain, M. Sra, J. Guo, R. Marques, R. Wu, J. Chiu, and C. Schmandt. 2016. Immersive scuba diving simulator using virtual reality. In Proceedings of the 29th Annual Symposium on User Interface Software and Technology. ACM, 729739.

[89] M. Karam, C. Branje, G. Nespoli, N. Thompson, F. A. Russo, and D. I. Fels. 2010. The emoti-chair: An interactive tactile music exhibit. In CHI'10 Extended Abstracts on Human Factors in Computing Systems (CHI EA'10). ACM, New York, 3069-3074. DOI : http://dx.doi.org/10.1145/1753846.1753919

[90] M. Kim, S. Lee, and S. Choi. 2012. Saliency-Driven Tactile Effect Authoring for Real-Time Visuotactile Feedback. Springer, Berlin,258-269. DOI : http://dx.doi.org/10.1007/978-3-642-31401-8_24

[91] S-J. Kim and D-H. Shin. 2016. The multisensory effects of atmospheric cues on online shopping satisfaction. In International Conference on HCI in Business, Government and Organizations. Springer, 406-416.

[92] S.-K. Kim. 2013. Authoring multisensorial content. Signal Processing: Image Communication 28, 2 (2013), $162-167$.

[93] Y. Kim, J. Cha, J. Ryu, and I. Oakley. 2010. A tactile glove design and authoring system for immersive multimedia. IEEE MultiMedia 17, 3 (July 2010), 34-45. DOI : http://dx.doi.org/10.1109/MMUL.2010.5692181

[94] K. Kolev, P. Tanskanen, P. Speciale, and M. Pollefeys. 2014. Turning mobile phones into 3D scanners. In The IEEE Conference on Computer Vision and Pattern Recognition (CVPR'14).

[95] P. T. Kovács, N. Murray, G. Rozinaj, Y. Sulema, and R. Rybárová. 2015. Application of immersive technologies for education: State of the art. In 2015 International Conference on Interactive Mobile Communication Technologies and Learning (IMCL'15). 283-288. DOI : http://dx.doi.org/10.1109/IMCTL.2015.7359604

[96] A. Krishna, L. Cian, and T. Sokolova. 2016. The power of sensory marketing in advertising. Current Opinion in Psychology 10 (2016), 142-147.

[97] S. Kuang and T. Zhang. 2014. Smelling directions: Olfaction modulates ambiguous visual motion perception. Scientific Reports 4 (2014), 5796.

[98] S. D. Kulkarni, C. J. Fisher, P. Lefler, A. Desai, S. Chakravarthy, E. R. Pardyjak, M. A. Minor, and J. M. Hollerbach. 2015. A full body steerable wind display for a locomotion interface. IEEE Transactions on Visualization and Computer Graphics 21, 10 (Oct. 2015), 1146-1159. DOI : http://dx.doi.org/10.1109/TVCG.2015.2424862

[99] S. D. Kulkarni, M. A. Minor, M. W. Deaver, and E. R. Pardyjak. 2007. Output feedback control of wind display in a virtual environment. In Proceedings 2007 IEEE International Conference on Robotics and Automation. 832-839. DOI : http://dx.doi.org/10.1109/ROBOT.2007.363089

[100] H. Morton L. 1962. Sensorama Simulator. (Aug. 28, 1962). US Patent 3,050,870.

[101] M.-K. Lai. 2015. Universal scent blackbox: Engaging visitors communication through creating olfactory experience at art museum. In Proceedings of the 33rd Annual International Conference on the Design of Communication (SIGDOC'15). ACM, New York, Article 27, 6 pages. DOI : http://dx.doi.org/10.1145/2775441.2775483

[102] B. Lee, S. Srivastava, R. Kumar, R. Brafman, and S. R. Klemmer. 2010. Designing with interactive example galleries. In Proceedings of the SIGCHI Conference on Human Factors in Computing Systems (CHI'10). ACM, New York, 2257-2266. DOI : http://dx.doi.org/10.1145/1753326.1753667 
[103] J. Lee and J. W. Park. 2013. A media art study using multi-sensory elements. In International Conference on HumanComputer Interaction. Springer, 277-281.

[104] J. Lee, J. Ryu, and S. Choi. 2009. Vibrotactile score: A score metaphor for designing vibrotactile patterns. In World Haptics 2009-3rd foint EuroHaptics Conference and Symposium on Haptic Interfaces for Virtual Environment and Teleoperator Systems. 302-307. DOI : http://dx.doi.org/10.1109/WHC.2009.4810816

[105] S.-H. Lee, J. E. Workman, and K. Jung. 2016. The influence of need for touch and gender on internet shopping attitudes among Korean consumers. International fournal of Fashion Design, Technology and Education 10, 2 (2016), 230-239.

[106] P. Lemmens, F. Crompvoets, D. Brokken, J. van den Eerenbeemd, and G. J. de Vries. 2009. A body-conforming tactile jacket to enrich movie viewing. In World Haptics 2009-3rd foint EuroHaptics Conference and Symposium on Haptic Interfaces for Virtual Environment and Teleoperator Systems. 7-12. DOI : http://dx.doi.org/10.1109/WHC.2009.4810832

[107] N. Leunis, M.-L. Boumans, B. Kremer, S. Din, E. Stobberingh, A. G. H. Kessels, and K. W. Kross. 2014. Application of an electronic nose in the diagnosis of head and neck cancer. Laryngoscope 124, 6 (2014), 1377-1381. DOI : http:// dx.doi.org/10.1002/lary.24463

[108] C.-H. Lin, S.-H. Huang, J.-L. Shih, A. Covaci, and G. Ghinea. 2017. Game-based learning effectiveness and motivation study between competitive and cooperative modes. In 2017 IEEE 17th International Conference on Advanced Learning Technologies (ICALT'17). IEEE, 123-127.

[109] CyberGlove Systems LLC. 2016. Home. Retrieved from http://www.cyberglovesystems.com/. Accessed: September 19, 2016.

[110] M. L. Dematté, D. Sanabria, and C. Spence. 2006. Cross-modal associations between odors and colors. Chemical Senses 31, 6 (2006), 531-538.

[111] N. Magnenat-Thalmann and U. Bonanni. 2006. Haptics in virtual reality and multimedia. IEEE MultiMedia 13, 3 (July 2006), 6-11. DOI : http://dx.doi.org/10.1109/MMUL.2006.56

[112] J. Martınez, A. S. Garcıa, M. Oliver, J. P. Molina, and P. González. 2014. VITAKI: A vibrotactile prototyping toolkit for virtual reality and video games. International fournal of Human-Computer Interaction 30, 11 (2014), 855-871. DOI : http://dx.doi.org/10.1080/10447318.2014.941272 arXiv:http://dx.doi.org/10.1080/10447318.2014.941272

[113] H. Matsukura, T. Nihei, and H. Ishida. 2011. Multi-sensorial field display: Presenting spatial distribution of airflow and odor. In 2011 IEEE Virtual Reality Conference. 119-122. DOI : http://dx.doi.org/10.1109/VR.2011.5759448

[114] H. Matsukura, T. Yoneda, and H. Ishida. 2013. Smelling screen: Development and evaluation of an olfactory display system for presenting a virtual odor source. IEEE Transactions on Visualization and Computer Graphics 19, 4 (April 2013), 606-615. DOI : http://dx.doi.org/10.1109/TVCG.2013.40

[115] R. E. Mayer and R. Moreno. 1998. A split-attention effect in multimedia learning: Evidence for dual processing systems in working memory. Fournal of Educational Psychology 90, 2 (1998), 312.

[116] D. Maynes-Aminzade. 2005. Edible bits: Seamless interfaces between people, data and food. In Conference on Human Factors in Computing Systems (CHI'05)-Extended Abstracts. Citeseer, 2207-2210.

[117] A. Mazzoni and N. Bryan-Kinns. 2016. Mood glove: A haptic wearable prototype system to enhance mood music in film. Entertainment Computing 17 (2016), 9-17. DOI : http://dx.doi.org/10.1016/j.entcom.2016.06.002

[118] D. McGookin and D. Escobar. 2016. Hajukone: Developing an open source olfactory device. In Proceedings of the 2016 CHI Conference Extended Abstracts on Human Factors in Computing Systems (CHI EA'16). ACM, New York, 1721-1728. DOI : http://dx.doi.org/10.1145/2851581.2892339

[119] M. McGrath and Q. Summerfield. 1985. Intermodal timing relations and audio-visual speech recognition by normalhearing adults. Journal of the Acoustical Society of America 77, 2 (1985), 678-685.

[120] B. Mesz, M. Sigman, and M. Trevisan. 2012. A composition algorithm based on crossmodal taste-music correspondences. Frontiers in Human Neuroscience 6 (2012), 71.

[121] T. A. Mikropoulos and A. Natsis. 2011. Educational virtual environments: A ten-year review of empirical research (1999-2009). Computers \& Education 56, 3 (2011), 769-780.

[122] T. Moon and G. J. Kim. 2004. Design and evaluation of a wind display for virtual reality. In Proceedings of the ACM Symposium on Virtual Reality Software and Technology (VRST'04). ACM, New York, 122-128. DOI : http://dx.doi.org/ $10.1145 / 1077534.1077558$

[123] G. M. Muntean, P. Perry, and L. Murphy. 2004. A new adaptive multimedia streaming system for all-IP multiservice networks. IEEE Transactions on Broadcasting 50, 1 (March 2004), 1-10. DOI : http://dx.doi.org/10.1109/TBC. 2004.824745

[124] T. Murakami, T. Person, C. L. Fernando, and K. Minamizawa. 2017. Altered touch: Miniature haptic display with force, thermal and tactile feedback for augmented haptics. In ACM SIGGRAPH 2017 Posters. ACM, 53.

[125] M. Murer, I. Aslan, and M. Tscheligi. 2013. LOLLio: Exploring taste as playful modality. In Proceedings of the 7th International Conference on Tangible, Embedded and Embodied Interaction (TEI'13). ACM, New York, 299-302. DOI : http://dx.doi.org/10.1145/2460625.2460675 
[126] M. M. Murray, C. M. Michel, R. Grave de Peralta, S. Ortigue, D. Brunet, S. Gonzalez Andino, and A. Schnider. 2004. Rapid discrimination of visual and multisensory memories revealed by electrical neuroimaging. Neuroimage 21, 1 (2004), 125-135.

[127] N. Murray, O. A. Ademoye, G. Ghinea, and G.-M. Muntean. 2017. A tutorial for olfaction-based multisensorial media application design and evaluation. ACM Computing Surveys (CSUR) 50, 5 (2017), 67.

[128] N. Murray, B. Lee, Y. Qiao, and G. Miro-Muntean. 2017. The impact of scent type on olfaction-enhanced multimedia quality of experience. IEEE Transactions on Systems, Man, and Cybernetics: Systems 47, 9 (2017), 2503-2515.

[129] N. Murray, B. Lee, Y. Qiao, and G.-M. Muntean. 2014. Multiple-scent enhanced multimedia synchronization. ACM Transactions on Multimedia Computing, Communications, and Applications (TOMM) 11, 1s (2014), 12.

[130] N. Murray, B. Lee, Y. Qiao, and G.-M. Muntean. 2016. Olfaction-enhanced multimedia: A survey of application domains, displays, and research challenges. ACM Computing Surveys (CSUR) 48, 4 (2016), 56.

[131] N. Murray, Y. Qiao, B. Lee, and G.-M. Muntean. 2014. User-profile-based perceived olfactory and visual media synchronization. ACM Transactions on Multimedia Computing, Communications, and Applications (TOMM) 10, 1s, Article 11 (Jan. 2014), 24 pages. DOI : http://dx.doi.org/10.1145/2540994

[132] T. Nakamoto. 2005. Study of odor recorder for dynamical change of odor. Chemical Senses 30 (2005), i254. DOI : http:// dx.doi.org/10.1093/chemse/bjh211

[133] T. Nakamoto, Y. Nakahira, H. Hiramatsu, and T. Moriizumi. 2001. Odor recorder using active odor sensing system. Sensors and Actuators B: Chemical 76, 1-3 (2001), 465-469. DOI : http://dx.doi.org/10.1016/S0925-4005(01)00587-1. Proceeding of the 8th International Meeting on Chemical Sensors (IMCS-8) - Part 1.

[134] T. Nakamoto, S. Otaguro, M. Kinoshita, M. Nagahama, K. Ohinishi, and T. Ishida. 2008. Cooking up an interactive olfactory game display. IEEE Computer Graphics and Applications 28, 1 (Jan. 2008), 75-78. DOI : http://dx.doi.org/10. 1109/MCG.2008.3

[135] H. Nakamura and H. Miyashita. 2012. Development and evaluation of interactive system for synchronizing electric taste and visual content. In Proceedings of the SIGCHI Conference on Human Factors in Computing Systems. ACM, $517-520$.

[136] T. Nakano, Y. Yoshioka, and Y. Yanagida. 2014. Effects of wind source configuration of wind displays on property of wind direction perception. In Proceedings of the Seventh International Conference on Advances in Computer-Human Interactions. Citeseer, 365-370.

[137] H. Y. Nam and M. Nitsche. 2013. Interactive installations as performance: Inspiration for HCI. In Proceedings of the 8th International Conference on Tangible, Embedded and Embodied Interaction (TEI'14). ACM, New York, 189-196. DOI : http://dx.doi.org/10.1145/2540930.2540976

[138] S. Nam and D. Fels. 2016. Design and Evaluation of an Authoring Tool and Notation System for Vibrotactile Composition. Springer International Publishing, Cham, 43-53. DOI : http://dx.doi.org/10.1007/978-3-319-40244-4_5

[139] S. Nanayakkara, E. Taylor, L. Wyse, and S. H. Ong. 2009. An enhanced musical experience for the deaf: Design and evaluation of a music display and a haptic chair. In Proceedings of the SIGCHI Conference on Human Factors in Computing Systems (CHI'09). ACM, New York, 337-346. DOI : http://dx.doi.org/10.1145/1518701.1518756

[140] T. Narumi. 2016. Multi-sensorial virtual reality and augmented human food interaction. In Proceedings of the 1st Workshop on Multi-sensorial Approaches to Human-Food Interaction. ACM, 1.

[141] T. Narumi, S. Nishizaka, T. Kajinami, T. Tanikawa, and M. Hirose. 2011. Augmented reality flavors: Gustatory display based on edible marker and cross-modal interaction. In Proceedings of the SIGCHI Conference on Human Factors in Computing Systems (CHI'11). ACM, New York, 93-102. DOI : http://dx.doi.org/10.1145/1978942.1978957

[142] A. Niijima and T. Ogawa. 2016. Study on control method of virtual food texture by electrical muscle stimulation. In Proceedings of the 29th Annual Symposium on User Interface Software and Technology (UIST'16 Adjunct). ACM, New York, 199-200. DOI : http://dx.doi.org/10.1145/2984751.2984768

[143] M. Nishizawa, W. Jiang, and K. Okajima. 2016. Projective-AR system for customizing the appearance and taste of food. In Proceedings of the 2016 workshop on Multimodal Virtual and Augmented Reality. ACM, 6.

[144] R. Nisimura, K. Hashimoto, H. Kawahara, and T. Irino. 2014. Proposal for an Interactive 3D Sound Playback Interface Controlled by User Behavior. Springer International Publishing, Cham, 446-450. DOI : http://dx.doi.org/10.1007/ 978-3-319-07857-1_78

[145] M. Obrist, P. Cesar, D. Geerts, T. Bartindale, and E. F. Churchill. 2015. Online video and interactive TV experiences. Interactions 22, 5 (Aug. 2015), 32-37. DOI : http://dx.doi.org/10.1145/2799629

[146] M. Obrist, R. Comber, S. Subramanian, B. Piqueras-Fiszman, C. Velasco, and C. Spence. 2014. Temporal, affective, and embodied characteristics of taste experiences: A framework for design. In Proceedings of the 32nd Annual ACM Conference on Human Factors in Computing Systems (CHI'14). ACM, New York, 2853-2862. DOI : http://dx.doi.org/10. $1145 / 2556288.2557007$

[147] M. Obrist, A. N. Tuch, and K. Hornbaek. 2014. Opportunities for odor: Experiences with smell and implications for technology. In Proceedings of the SIGCHI Conference on Human Factors in Computing Systems (CHI'14). ACM, New York, 2843-2852. DOI : http://dx.doi.org/10.1145/2556288.2557008 
[148] M. Obrist, C. Velasco, C. Vi, N. Ranasinghe, A. Israr, A. Cheok, C. Spence, and P. Gopalakrishnakone. 2016. Sensing the future of HCI: Touch, taste, and smell user interfaces. Interactions 23, 5 (Aug. 2016), 40-49. DOI : http://dx.doi. org/10.1145/2973568

[149] S. Oviatt. 2006. Human-centered design meets cognitive load theory: Designing interfaces that help people think. In Proceedings of the 14th ACM International Conference on Multimedia (MM'06). ACM, New York, 871-880. DOI : http:// dx.doi.org/10.1145/1180639.1180831

[150] S. Oviatt, R. Coulston, S. Tomko, B. Xiao, R. Lunsford, M. Wesson, and L. Carmichael. 2003. Toward a theory of organized multimodal integration patterns during human-computer interaction. In Proceedings of the 5th International Conference on Multimodal Interfaces (ICMI’03). ACM, New York, 44-51. DOI : http://dx.doi.org/10.1145/958432.958443

[151] Panocam3D.com. 2017. Stereoscopic and Panoramic Video Cameras - 3D 360 Videos Production. Retrieved from http://www.panocam3d.com. Accessed March 19, 2017.

[152] S. A. Panëels, J. C. Roberts, and P. J. Rodgers. 2010. HITPROTO: A tool for the rapid prototyping of haptic interactions for haptic data visualization. In 2010 IEEE Haptics Symposium. 261-268. DOI : http://dx.doi.org/10.1109/HAPTIC.2010. 5444647

[153] C. V. Parise. 2016. Crossmodal correspondences: Standing issues and experimental guidelines. Multisensory Research 29, 1-3 (2016), 7-28. DOI : http://dx.doi.org/10.1163/22134808-00002502

[154] I. Park and M. J. Hannafin. 1993. Empirically-based guidelines for the design of interactive multimedia. Educational Technology Research and Development 41, 3 (1993), 63-85.

[155] R. A. Pieretti, S. D. Kaul, R. M. Zarchy, and L. M. O’Hanlon. 2015. Using a multimodal approach to facilitate articulation, phonemic awareness, and literacy in young children. Communication Disorders Quarterly 36, 3 (2015), 131-141.

[156] K.-H. Plattig and J. Innitzer. 1976. Taste qualities elicited by electric stimulation of single human tongue papillae. Pflügers Archiv 361, 2 (1976), 115-120.

[157] V. Potkonjak, M. Gardner, V. Callaghan, P. Mattila, C. Guetl, V. M. Petrović, and K. Jovanović. 2016. Virtual laboratories for education in science, technology, and engineering: A review. Computers \& Education 95 (2016), 309-327.

[158] M. Prasad, P. Taele, D. Goldberg, and T. A. Hammond. 2014. HaptiMoto: Turn-by-turn haptic route guidance interface for motorcyclists. In Proceedings of the 32nd Annual ACM Conference on Human Factors in Computing Systems (CHI'14). ACM, New York, 3597-3606. DOI : http://dx.doi.org/10.1145/2556288.2557404

[159] N. Ranasinghe, A. D. Cheok, and R. Nakatsu. 2012. Taste/IP: The sensation of taste for digital communication. In Proceedings of the 14th ACM International Conference on Multimodal Interaction. ACM, 409-416.

[160] N. Ranasinghe and E. Yi-Luen Do. 2016. Virtual sweet: Simulating sweet sensation using thermal stimulation on the tip of the tongue. In Proceedings of the 29th Annual Symposium on User Interface Software and Technology (UIST'16 Adjunct). ACM, New York, 127-128. DOI : http://dx.doi.org/10.1145/2984751.2985729

[161] N. Ranasinghe, P. Jain, S. Karwita, and E. Yi-Luen Do. 2017. Virtual lemonade: Let's teleport your lemonade!. In Proceedings of the 11th International Conference on Tangible, Embedded, and Embodied Interaction (TEI'17). ACM, New York, 183-190. DOI : http://dx.doi.org/10.1145/3024969.3024977

[162] N. Ranasinghe, T. N. T. Nguyen, Y. Liangkun, L.-Y. Lin, D. Tolley, and E. Y-. Do. 2017. Vocktail: A virtual cocktail for pairing digital taste, smell, and color sensations. In Proceedings of the 2017 ACM on Multimedia Conference (MM'17). ACM, New York, 1139-1147. DOI : http://dx.doi.org/10.1145/3123266.3123440

[163] S. Rasool and A. Sourin. 2016. Real-time haptic interaction with RGBD video streams. Visual Computer 32, 10 (2016), 1311-1321

[164] E. Richard, A. Tijou, P. Richard, and J.-L. Ferrier. 2006. Multi-modal virtual environments for education with haptic and olfactory feedback. Virtual Reality 10, 3-4 (2006), 207-225.

[165] L. A. Ross, D. Saint-Amour, V. M. Leavitt, D. C. Javitt, and J. J. Foxe. 2007. Do you see what I am saying? Exploring visual enhancement of speech comprehension in noisy environments. Cerebral Cortex 17, 5 (2007), 1147-1153.

[166] J. Ryu and S. Choi. 2008. posVibEditor: Graphical authoring tool of vibrotactile patterns. In 2008 IEEE International Workshop on Haptic Audio visual Environments and Games. 120-125. DOI : http://dx.doi.org/10.1109/HAVE. 2008.4685310

[167] F. Röck, N. Barsan, and U. Weimar. 2008. Electronic nose: Current status and future trends. Chemical Reviews 108, 2 (2008), 705-725. DOI :http://dx.doi.org/10.1021/cr068121q arXiv:http://dx.doi.org/10.1021/cr068121qPMID: 18205411.

[168] J. Saboune and J. M. Cruz-Hernandez. 2015. Method and apparatus to generate haptic feedback from video content analysis. (June 23, 2015). US Patent 9,064,385.

[169] E. B. Saleme, J. R. Celestrini, and C. A. Saibel Santos. 2017. Time evaluation for the integration of a gestural interactive application with a distributed mulsemedia platform. In Proceedings of the 8th ACM on Multimedia Systems Conference (MMSys'17). ACM, New York, 308-314. DOI : http://dx.doi.org/10.1145/3083187.3084013 
[170] N. A. Samshir, N. Johari, K. Karunanayaka, and A. D. Cheok. 2016. Thermal sweet taste machine for multisensory internet. In Proceedings of the 4th International Conference on Human Agent Interaction. ACM, 325-328.

[171] K. Sato, H. Kajimoto, N. Kawakami, and S. Tachi. 2007. Electrotactile display for integration with kinesthetic display. In The 16th IEEE International Symposium on Robot and Human Interactive Communication (RO-MAN'07). 3-8. DOI : http://dx.doi.org/10.1109/ROMAN.2007.4415044

[172] O. Schneider, K. MacLean, C. Swindells, and K. Booth. 2017. Haptic experience design: What hapticians do and where they need help. International fournal of Human-Computer Studies 107 (2017), 5-21.

[173] O. Schneider, S. Zhao, and A. Israr. 2015. FeelCraft: User-Crafted Tactile Content. Springer Japan, Tokyo, 253-259. DOI : http://dx.doi.org/10.1007/978-4-431-55690-9_47

[174] O. S. Schneider, A. Israr, and K. E. MacLean. 2015. Tactile animation by direct manipulation of grid displays. In Proceedings of the 28th Annual ACM Symposium on User Interface Software \& Technology (UIST'15). ACM, New York, 21-30. DOI : http://dx.doi.org/10.1145/2807442.2807470

[175] O.S. Schneider and K. E. MacLean. 2016. Studying design process and example use with Macaron, a web-based vibrotactile effect editor. In 2016 IEEE Haptics Symposium (HAPTICS'16). 52-58. DOI : http://dx.doi.org/10.1109/HAPTICS. 2016.7463155

[176] H. Seifi, C. Anthonypillai, and K. E. MacLean. 2014. End-user customization of affective tactile messages: A qualitative examination of tool parameters. In 2014 IEEE Haptics Symposium (HAPTICS'14). 251-256. DOI : http://dx.doi. org/10.1109/HAPTICS.2014.6775463

[177] H. Seifi, K. Zhang, and K. E. MacLean. 2015. VibViz: Organizing, visualizing and navigating vibration libraries. In 2015 IEEE World Haptics Conference (WHC'15). 254-259. DOI : http://dx.doi.org/10.1109/WHC.2015.7177722

[178] A. Seigneuric, K. Durand, T. Jiang, J-Y. Baudouin, and B. Schaal. 2010. The nose tells it to the eyes: Crossmodal associations between olfaction and vision. Perception 39, 11 (2010), 1541-1554.

[179] L. Shams and A. R. Seitz. 2008. Benefits of multisensory learning. Trends in Cognitive Sciences 12, 11 (2008), 411-417.

[180] R. Sigrist, G. Rauter, R. Riener, and P. Wolf. 2013. Augmented visual, auditory, haptic, and multimodal feedback in motor learning: A review. Psychonomic Bulletin \& Review 20, 1 (2013), 21-53.

[181] J. M. Silva, M. Orozco, J. Cha, A. El Saddik, and E. M. Petriu. 2013. Human perception of haptic-to-video and hapticto-audio skew in multimedia applications. ACM Transactions on Multimedia Computing, Communications, and Applications (TOMM) 9, 2, Article 9 (May 2013), 16 pages. DOI : http://dx.doi.org/10.1145/2457450.2457451

[182] J. Simner, C. Cuskley, and S. Kirby. 2010. What sound does that taste? Cross-modal mappings across gustation and audition. Perception 39, 4 (2010), 553-569.

[183] M. Simsek, A. Aijaz, M. Dohler, J. Sachs, and G. Fettweis. 2016. 5G-enabled tactile internet. IEEE fournal on Selected Areas in Communications 34, 3 (March 2016), 460-473. DOI : http://dx.doi.org/10.1109/JSAC.2016.2525398

[184] B. G. Slocombe, D. A. Carmichael, and J. Simner. 2016. Cross-modal tactile-taste interactions in food evaluations. Neuropsychologia 88 (2016), 58-64.

[185] E. R. Spangenberg, B. Grohmann, and D. E. Sprott. 2005. It's beginning to smell (and sound) a lot like Christmas: The interactive effects of ambient scent and music in a retail setting. fournal of Business Research 58, 11 (2005), 1583-1589. DOI : https://doi.org/10.1016/j.jbusres.2004.09.005

[186] C. Spence. 2011. Crossmodal correspondences: A tutorial review. Attention, Perception, \& Psychophysics 73, 4 (2011), 971-995.

[187] C. Spence and C. Ho. 2015. Multisensory information processing. In APA Handbook of Human Systems Integration, D. A. Boehm-Davis, F. T. Durso, and J. D. Lee (Eds.). American Psychological Association, Washington, DC, 435-448. DOI : $10.1037 / 14528-027$

[188] C. Spence, X. Wan, A. Woods, C. Velasco, J. Deng, J. Youssef, and O. Deroy. 2015. On tasty colours and colourful tastes? Assessing, explaining, and utilizing crossmodal correspondences between colours and basic tastes. Flavour 4, 1 (July 2015), 23. DOI : http://dx.doi.org/10.1186/s13411-015-0033-1

[189] B. E. Stein. 2016. The New Handbook of Multisensory Processing. MIT Press, Cambridge, MA.

[190] B. E. Stein, T. R. Stanford, and B. A. Rowland. 2014. Development of multisensory integration from the perspective of the individual neuron. Nature Reviews Neuroscience 15, 8 (2014), 520-535.

[191] R. Steinmetz. 1996. Human perception of jitter and media synchronization. IEEE fournal on Selected Areas in Communications 14, 1 (Jan. 1996), 61-72. DOI : http://dx.doi.org/10.1109/49.481694

[192] N. R. Stiles and S. Shimojo. 2014. Auditory sensory substitution is intuitive and automatic with texture stimuli.Scientific Reports 5 (2014), 15628-15628.

[193] T. Stockhammer. 2011. Dynamic adaptive streaming over HTTP -: Standards and design principles. In Proceedings of the 2nd Annual ACM Conference on Multimedia Systems (MMSys'11). ACM, New York, 133-144. D0I : http://dx.doi. org/10.1145/1943552.1943572 
[194] Y. Sulema. 2016. Mulsemedia vs. multimedia: State of the art and future trends. In 2016 International Conference on Systems, Signals and Image Processing (IWSSIP'16). IEEE, 1-5.

[195] C. Suzuki, T. Narumi, T. Tanikawa, and M. Hirose. 2014. Affecting tumbler: Affecting our flavor perception with thermal feedback. In Proceedings of the 11th Conference on Advances in Computer Entertainment Technology (ACE'14). ACM, New York, Article 19, 10 pages. DOI : http://dx.doi.org/10.1145/2663806.2663825

[196] R. Suzuki, S. Homma, E. Matsuura, and K-i. Okada. 2014. System for presenting and creating smell effects to video. In Proceedings of the 16th International Conference on Multimodal Interaction (ICMI'14). ACM, New York, 208-215. DOI : http://dx.doi.org/10.1145/2663204.2663269

[197] C. Swindells, S. Pietarinen, and A. Viitanen. 2014. Medium fidelity rapid prototyping of vibrotactile haptic, audio and video effects. In 2014 IEEE Haptics Symposium (HAPTICS'14). 515-521. DOI : http://dx.doi.org/10.1109/HAPTICS. 2014.6775509

[198] B. Tag, T. Goto, K. Minamizawa, R. Mannschreck, H. Fushimi, and K. Kunze. 2017. atmoSphere: Mindfulness over haptic-audio cross modal correspondence. In Proceedings of the 2017 ACM International foint Conference on Pervasive and Ubiquitous Computing and Proceedings of the 2017 ACM International Symposium on Wearable Computers. ACM, 289-292.

[199] A. Tatematsu, Y. Ishibashi, N. Fukushima, and S. Sugawara. 2010. QoE assessment in haptic media, sound and video transmission: Influences of network latency. In 2010 IEEE International Workshop Technical Committee on Communications Quality and Reliability (CQR'10). 1-6. DOI : http://dx.doi.org/10.1109/CQR.2010.5619913

[200] V. A. Thompson and A. Paivio. 1994. Memory for pictures and sounds: Independence of auditory and visual codes. Canadian fournal of Experimental Psychology/Revue Canadienne de Psychologie Expérimentale 48, 3 (1994), 380 .

[201] C. Timmerer, J. Gelissen, M. Waltl, and H. Hellwagner. 2009. Interfacing with virtual worlds. Network and Electronic Media Summit (2009).

[202] N. Turoman, C. Velasco, Y.-C. Chen, P.-C. Huang, and C. Spence. 2018. Symmetry and its role in the crossmodal correspondence between shape and taste. Attention, Perception, \& Psychophysics 80, 3 (2018), 738-751.

[203] S. U. Rehman, J. Sun, L. Liu, and H. Li. 2008. Turn your mobile into the ball: Rendering live football game using vibration. IEEE Transactions on Multimedia 10, 6 (Oct. 2008), 1022-1033. DOI : http://dx.doi.org/10.1109/TMM.2008. 2001352

[204] H. Uematsu, D. Ogawa, R. Okazaki, T. Hachisu, and H. Kajimoto. 2016. HALUX: Projection-based interactive skin for digital sports. In ACM SIGGRAPH 2016 Emerging Technologies (SIGGRAPH’16). ACM, New York, Article 10, 2 pages. DOI : http://dx.doi.org/10.1145/2929464.2929479

[205] E. Van der Burg, C. N. L. Olivers, A. W. Bronkhorst, and J. Theeuwes. 2008. Pip and pop: Nonspatial auditory signals improve spatial visual search. Journal of Experimental Psychology: Human Perception and Performance 34, 5 (2008), 1053.

[206] C. Velasco, M. Obrist, O. Petit, and C. Spence. 2018. Multisensory technology for flavor augmentation: A mini review. Frontiers in Psychology 9 (2018), 26.

[207] C. Velasco, A. T. Woods, O. Petit, A. D. Cheok, and C. Spence. 2016. Crossmodal correspondences between taste and shape, and their implications for product packaging: A review. Food Quality and Preference 52 (2016), 17-26. DOI : http://dx.doi.org/10.1016/j.foodqual.2016.03.005

[208] C. Thanh Vi, D. Ablart, D. Arthur, and M. Obrist. 2017. Gustatory interface: The challenges of 'how' to stimulate the sense of taste. In Proceedings of 2nd ACM SIGCHI International Workshop on Multisensory Approaches to Human-Food Interaction (MHFI'17). ACM, 29-33.

[209] G. von Békésy. 1964. Olfactory analogue to directional hearing. fournal of Applied Physiology 19, 3 (1964), 369-373. Retrieved from http://jap.physiology.org/content/19/3/369.

[210] M. Waltl. 2010. Enriching Multimedia with Sensory Effects: Annotation and Simulation Tools for the Representation of Sensory Effects. VDM Verlag, Saarbrücken, Germany.

[211] M. Waltl, B. Rainer, C. Timmerer, and H. Hellwagner. 2013. An end-to-end tool chain for sensory experience based on MPEG-V. Signal Processing: Image Communication 28, 2 (2013), 136-150. DOI : http://dx.doi.org/10.1016/j.image. 2012.10.009

[212] Q. J. Wang and C. Spence. 2017. The role of pitch and tempo in sound-temperature crossmodal correspondences. Multisensory Research 30, 3-5 (2017), 307-320.

[213] O. Wright, Y. Jraissati, and D. Özçelik. 2017. Cross-modal associations between color and touch: Mapping haptic and tactile terms to the surface of the Munsell color solid. Multisensory Research 30, 7-8 (2017), 691-715. DOI : http:// dx.doi.org/10.1163/22134808-00002589

[214] T. Yamanaka, R. Matsumoto, and T. Nakamoto. 2003. Fundamental study of odor recorder for multicomponent odor using recipe exploration method based on singular value decomposition. IEEE Sensors fournal 3, 4 (Aug. 2003), 468474. DOI : http://dx.doi.org/10.1109/JSEN.2003.815778 
[215] Z. Yuan, T. Bi, G. M. Muntean, and G. Ghinea. 2015. Perceived synchronization of mulsemedia services. IEEE Transactions on Multimedia 17, 7 (July 2015), 957-966. DOI : http://dx.doi.org/10.1109/TMM.2015.2431915

[216] Z. Yuan, G. Ghinea, and G.-M. Muntean. 2015. Beyond multimedia adaptation: Quality of experience-aware multisensorial media delivery. IEEE Transactions on Multimedia 17, 1 (2015), 104-117.

[217] Z. Yuan, G. Ghinea, and G. M. Muntean. 2015. Beyond multimedia adaptation: Quality of experience-aware multisensorial media delivery. IEEE Transactions on Multimedia 17, 1 (Jan. 2015), 104-117. DOI : http://dx.doi.org/10.1109/ TMM.2014.2371240

[218] J. S. Zelek, S. Bromley, D. Asmar, and D. Thompson. 2003. A haptic glove as a tactile-vision sensory substitution for wayfinding. Journal of Visual Impairment and Blindness 97, 10 (2003), 621-632.

[219] Q. Zeng, Y. Ishibashi, N. Fukushima, S. Sugawara, and K. E. Psannis. 2013. Influences of inter-stream synchronization errors among haptic media, sound, and video on quality of experience in networked ensemble. In 2013 IEEE 2nd Global Conference on Consumer Electronics (GCCE'13). 466-470. DOI : http://dx.doi.org/10.1109/GCCE.2013.6664891

[220] S. E. Zohora, A. M. Khan, and N. Hundewale. 2013. Chemical Sensors Employed in Electronic Noses: A Review. Springer, Berlin,177-184. DOI: http://dx.doi.org/10.1007/978-3-642-31600-5_18

[221] L. Zou, R. Trestian, and G. M. Muntean. 2015. E2DOAS: User experience meets energy saving for multi-device adaptive video delivery. In 2015 IEEE Conference on Computer Communications Workshops (INFOCOM WKSHPS'15). 444-449. DOI : http://dx.doi.org/10.1109/INFCOMW.2015.7179425

Received September 2017; revised March 2018; accepted June 2018 